Article

\title{
Landscape Risk Assessment Model and Decision Support System for the Protection of the Natural and Cultural Heritage in the Eastern Mediterranean Area
}

\author{
Maria Gabriella Trovato *, Dana Ali, Jessica Nicolas, Ammar El Halabi ${ }^{\dagger}$ and Sarah Meouche $\ddagger$ \\ Landscape Design and Ecosystem Management, Faculty of Agricultural and Food Sciences, American \\ University of Beirut, Riad El-Solh, Beirut 1107-2020, Lebanon; dra10@mail.aub.edu (D.A.); \\ jessicatnicolas@gmail.com (J.N.); aae48@mail.aub.edu (A.E.H.); sarah.meoushe@gmail.com (S.M.) \\ * Correspondence: mt63@aub.edu.lb; Tel.: +961-78827535 \\ + Current Affiliation: Freelance Software Developer, Beirut, Lebanon. \\ $\ddagger$ Current Affiliation: Freelance Landscape Architect, Beirut, Lebanon.
}

Received: 18 July 2017; Accepted: 21 October 2017; Published: 3 November 2017

\begin{abstract}
In recent years, the competition of uses for scarce and highly valuable natural resources, and the frequency and severity of natural and technological disasters have increased, and this trend is likely to worsen in the years to come. In the Mediterranean area, especially in its Eastern part, the high human exploitation driven by different economic sectors and interests is resulting in intensive use of the land and its resources. Tourism intensification, rapid growth of urban settlement and related sprawl, movement and displacement of populations, rural abandonment, and adoption of different agricultural techniques are profoundly and rapidly changing the landscape character of the East Mediterranean. In view of the risks to cultural and natural heritage, a Landscape Risk Assessment Model (LRA) and Decision Support System (LDSS) were developed through the MedScapes-ENPI project. This paper reports the experience conducted at the Landscape Design and Ecosystem Management Department (LDEM) in the American University of Beirut (AUB) in developing the two tools, LRA and LDSS. It aims to provide insight into the methodology designed and tested during the length of the project to take into account the protection of landscapes of particular interest as well as the rational planning of all the landscapes with special emphasis on the use of natural resources. The assessment was applied in the study area of each partner country of the ENPI project, allowing for a better understanding of the implications in land-use and conservation decision-making.
\end{abstract}

Keywords: Landscape Risk Assessment Model; Landscape Decision Support System; East Med landscape

\section{Introduction}

In the Mediterranean area, especially in its Eastern part, the high human exploitation driven by different economic sectors and interests is resulting in intensive use of the land and its resources. The consequences are evident and the fact is that never before have we transformed so much territory as in recent years and at such a fast pace [1]. The MedScapes project, through the development of a methodology to assess and evaluate the landscape of the East Mediterranean and its threats (Landscape Character Assessment (LCA), Landscape Risk Assessment (LRA), Landscape Decision Support System (LDSS)) aimed to introduce the concept of landscape planning as a tool to integrate the different features of the region (the ecological and cultural ones) to support landscape strategies and planning. Working on the implementation of the European Landscape Convention (ELC, 2000 [2]), it intended to support local authorities and non-governmental organization with the development of scientific tools designed for the protection, conservation, and management of the natural and cultural heritage of the region. 
The objective of the present study was to asses, using GIS, the loss of the landscape value of the chosen areas in the four partner countries under the pressure of selected and measured hazards, and to develop a landscape spatial decision support system to support decision-making, and assist stakeholders in comparative assessment and selection of options for change. The review of already implemented and tested Risk Assessment (RA) and Decision Support System (DSS) approaches revealed that most of them are models for ecological analysis and assessment (i.e., EcoRa, Ecological risk assessment [3], DS WMVOC Environmental Risk Assessment for Decision Support System for water management in the vicinity of open cast mines [4]). Some of them are directed to produce integrated multi-risk maps to achieve more effective spatial planning procedures in areas prone to natural disasters (i.e., ARMONIA, 2007 [5]), to encourage climate adaptation planning in coastal areas (i.e., DESYCO, 2015 [6]), or to intervene at a regional scale to support environmental risk assessment and management (i.e., SYRIADE, 2012 Spatial decision support system for Regional risk Assessment of Degraded land [7]).

Despite the fact that the knowledge, recognition, and awareness of a landscape as a value have become a very distinctive topic in the last decades, there is still a deficiency of tools specifically designed for the landscape issue. Research studies have been conducted on the assessment of the landscape value [8] and have been motivated by the need to inform and enhance land use planning and environmental management. For example, typologies of landscape values have been developed and implemented to inform forest management [9-11], national parks and protected area management [12], urban park planning [13], residential and tourism development [14,15], coastal area management [16], rural development $[17,18]$, and climate change risk [19]. Based on the consideration that the value of a landscape is an important issue for landscape protection planning [20] and that it is a key problem pertaining to sustainable landscape management [21-23], we concentrated our study on the assessment of the loss and depletion of landscape value in order to be able to produce scenarios for more coordinated planning.

This paper describes the methodology we developed and implemented to analyze the landscape hazards, landscape values, and landscape risk and to build an interactive web-based interface, where the users could view the results of the Landscape Character Assessment (LCA) and LRA and alter scenarios in the LRA pertaining to intensification of urban sprawl patterns hazard and Landscape Value (LV). This method was built upon the results of the LCA conducted in the four Eastern Mediterranean partner countries of the project (Cyprus, Greece, Jordan, and Lebanon), and takes into account two main components: the landscape value, as a result of natural and cultural elements; and the severity of risks which cause a threat/pressure for change. Four hazard categories were chosen and assessed: desertification, intensification of urban sprawl patterns, erosion, and forest fire.

In this study, the landscape value is quantitatively evaluated by using three different parameters (Dominant habitat, Naturalness, and Habitat Continuity), while the hazards are quantitatively and qualitatively measured. The risk is assessed with reference to the potential occurrence of the previously mentioned hazards. Landscape hazard frequency may impoverish the value of the landscape, directly depleting natural resources and features (trees, woods, streams), altering ecological functions by landscape fragmentation, and eroding high quality agricultural land [24].

This study presents some limitations due to the complexity in comparing and interrelating data from four different countries, the difficulty in acquiring the same type of materials in the four partner countries, and the impossibility of monitoring the changes through time due to the lack of data. This paper acknowledges the 'profound transition' that Antrop [25] asserts the landscape concept is passing through and it is visible on the indicators chosen and the weight we allocate to them. 


\section{Materials and Methods}

\subsection{Study Area and Available Data}

The areas investigated by the RA and LDSS were the Level 1 LCA defined zones in the four partner countries of the project (Figures 1 and 2).

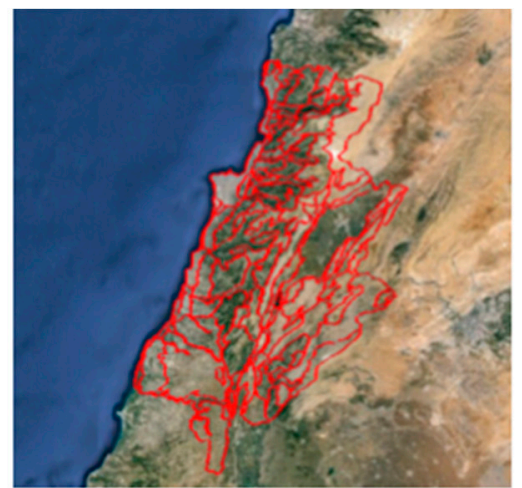

(a)

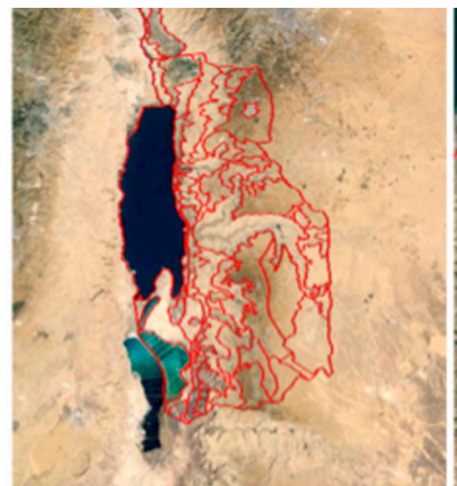

(b)

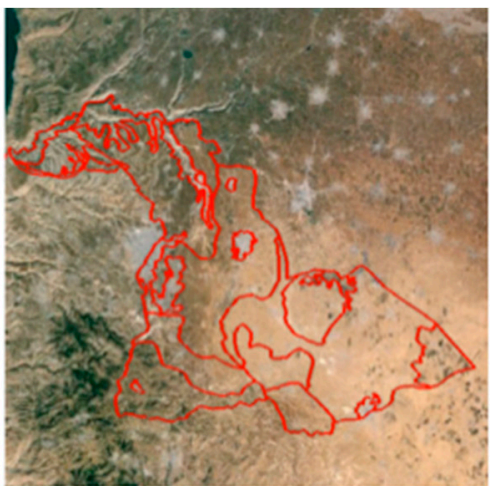

(c)

Figure 1. Risk assessment model study areas in the partner countries. (a) Lebanon Area: $4747 \mathrm{~km}^{2}$; (b) Jordan-Mujib Area: $6790 \mathrm{~km}^{2}$; (c) Jordan—Al-Yarmuk Area: $3800 \mathrm{~km}^{2}$.

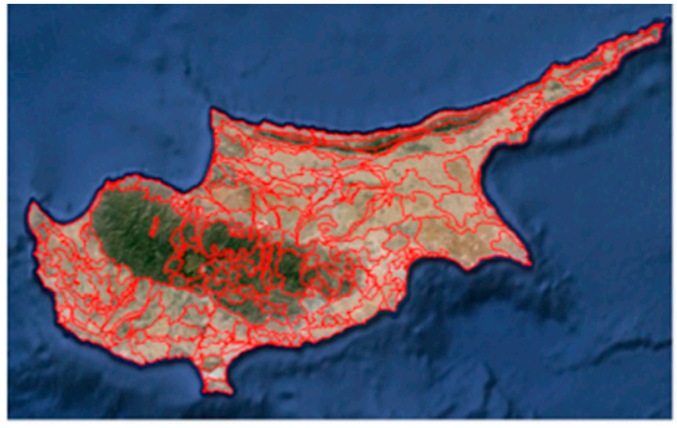

(a)

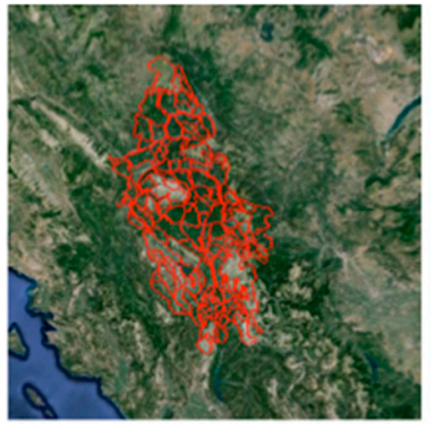

(b)

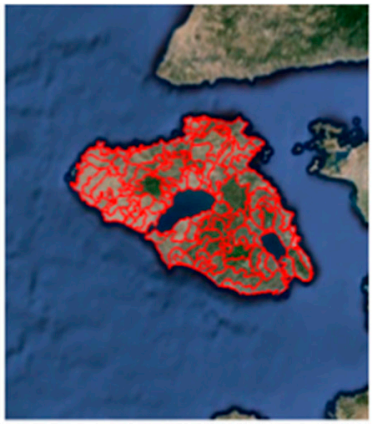

(c)

Figure 2. Risk assessment model study areas in the partner countries. (a) Cyprus Area: $9251 \mathrm{~km}^{2}$; (b) Greece-Epirus Area: $6790 \mathrm{~km}^{2}$; (c) Greece-Lesvos Area: $1632 \mathrm{~km}^{2}$.

The study area in Lebanon represents $45 \%$ of the country and it encompasses four distinct geomorphological regions: the coastal plain, Lebanon Mountain range, Bekaa Valley, and the Anti-Lebanon mountain range.

In Jordan, two areas were chosen: the first, Mujib, is located within Madaba and Kerak governorates and it extends from the Jordan Rift Valley (JRV) escarpment in the west, at $420 \mathrm{~m}$ below sea level, to the central highlands plateau in the east, with elevations exceeding $700 \mathrm{~m}$ above sea level; the second, Al-Yarmouk catchment area, is located in the North-West part of Jordan and it is comprised of large urban centers (Irbid and Al Ramtha) in addition to extensive agricultural activities, and it includes unique heritage and historical places of Jordan.

Two areas were also selected in Greece: Epirus, located in the Region of Epirus, predominantly mountainous and characterized by significant landscape diversity (high mountains, cultivated settled areas, and grazed pastures); and Lesvos, the third largest island in the Aegean Sea, with approximately $41 \%$ of the area planted with olive, $34 \%$ with maquis and garrigue, $17 \%$ with forest, and $3 \%$ with other crops, while the remaining land has various uses such as constructions, wetlands, etc. 
As for Cyprus, the entire island was part of the study. The island is divided into three geomorphological zones: the Troodos Mountain, the Pentadaktylos Range, and the Mesaoria plain.

The six areas in the four countries present differences in geomorphology, land use, settlement patterns, and economy. This diversity had to be taken into consideration while developing our tools and constructing a conceptual model holistically.

\subsection{Methodology}

The methodology was the result of an extensive analysis and investigation throughout prevailing studies and RA-DSS models developed and implemented in past years. Disaster management became of particular importance in recent years [26] and disaster risk reduction is a world challenge. The 1992 Earth Summit on Environment and Development in Rio de Janeiro, Brazil, provided a venue for international recognition of the connection between development, environment, and disaster risk reduction [27]. Thereafter, passing from the 'environmental justice' perspective and the Environmental Protection Agency, EPA, the international research evolved and moved towards considering the cumulative impacts of multiple hazards. In Europe, the European Commission has been encouraging studies on natural disasters since the early 1980s. Research under the Seventh Framework Program aimed to reduce and mitigate the environmental, social, and economic effects of natural disasters through a holistic multidisciplinary approach in which aspects of hazards/multi-hazards, vulnerability, and risk assessment were addressed in an integrated manner [28].

The literature on sustainability and hazard or risk mitigation is now extensive and includes academic, practitioner, and governmental consideration of the need to adopt sustainable approaches to hazard and risk management [29]. While environmental risk assessment is broadly applied to identify the danger the environment is exposed to in relation to the different types of hazards, on the other hand, landscape risk assessment related to the landscape value is an under-evaluated and investigated tool. Landscape risk appears to be a more uncertain issue where approaches are focused on the visual impact of changes in land use due to human activities (i.e., the construction of new buildings or infrastructures) [30]. Overall, very few publications connect the assessment of landscape with land use decision-making. For example, MULBO model framework (Multi-criteria Landscape Assessment and Optimization) is a spatially explicit decision support method on the basis of risk evaluations for landscape function that aims to establish optimal land use patterns as scenarios that are balanced compromises between conflicting goals for the reduction of assessed risks [21].

As a result of the ELC, the Discrete Choice Experiment (DCE) method was adopted to enrich the process of landscape decision-making mainly due to its flexibility and ability to take into account the multidimensional nature of landscapes and to provide detailed information about marginal changes in landscapes as well as trade-offs between the landscape attributes themselves and between the landscape attributes and money [31]. The DCE seems to better respond to the need of experts and policy-makers in finding a way to quantify the value of landscapes to the local residents and to incorporate these values into their landscape protection, management, and planning decisions [32]. On the other hand, the DCE does not take into account and does not assess the landscape changes in relation to the different types of hazards.

The LRA-LDSS framework, presented in this paper, incorporates some important key aspects:

- The LRA was conducted at the scale of Landscape Descriptive Units (LDUs) that were delineated by the LCA process. This allowed the tool to visualize the hazard impact for the different Landscape Character Types.

- The LRA was formulated through a risk equation as the result of the relation between the two factors Hazard and Landscape Value

- The framework made use of a two-dimensional matrix for a risk legend, borrowed from the ARMONIA EU project, that was reworked and adapted to our study. 
- The LRA-LDSS used the scenario-based approach to spatially visualize a series of possible physical landscape transformations due to the increased intensity of a landscape hazard.

Our conceptual framework is the result of the relation between LCA, LRA, and LDSS and describes the operative steps used to derive hazards maps, landscape values maps, risk maps, and scenarios' maps (Figure 3). It is organized as per the following scheme:

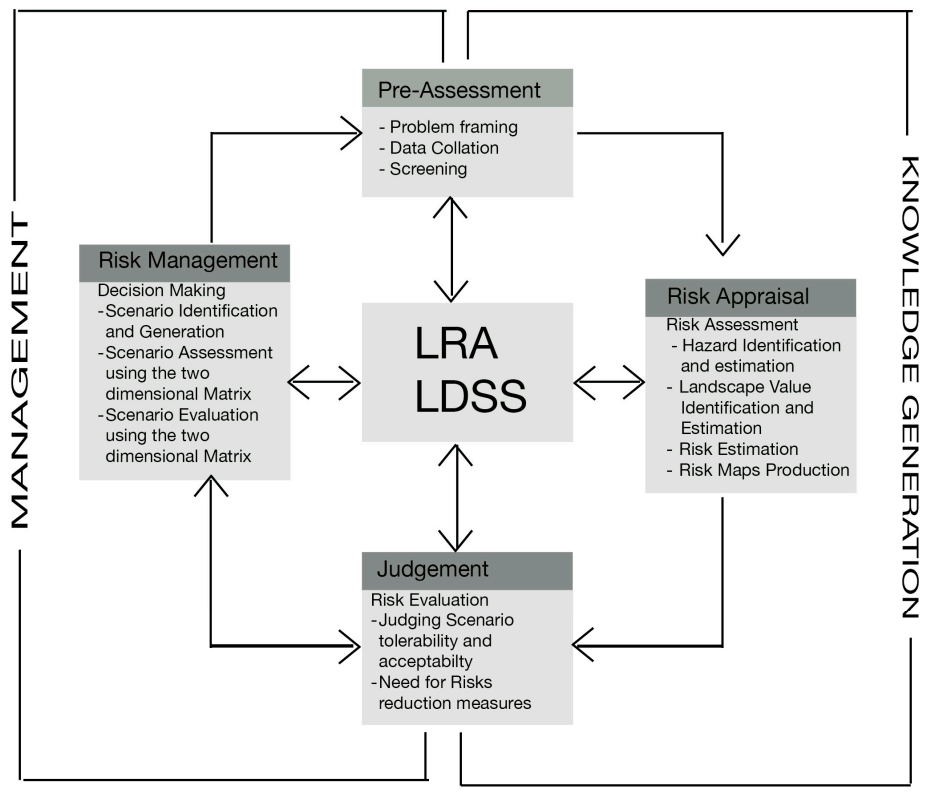

Figure 3. Landscape Risk Assessment conceptual framework.

\section{Landscape Risk Assessment (LRA) and Landscape Decision Support System (LDSS)}

The Landscape Risk Assessment was conducted in phases: Pre-Assessment, Risk Appraisal, Judgment/Risk Evaluation, and Risk Management.

The Pre-Assessment allowed us to frame the aims of the model, to verify the availability of data per countries, to collate the LCA results, and to test and assess the correct model in line with the objective of the project.

The Risk Appraisal was based on hazard identification, hazard ranking and assessment of magnitude per Landscape Descriptive Units (LDUs), Landscape Values identification, and assessment per each of the LDUs.

The Judgment/Risk Evaluation was conducted by determining the significance of the estimated risks in relation to the loss of the assessed Landscape Values. It was carried out by applying the MedScapes risk equation: Risk $=$ Hazard $\times$ Landscape Value derived from the original equation that we borrowed from the EU project ARMONIA [5].

The Risk Management phase let the user to build scenarios through the LDSS Web user's interface. The Landscape DSS support future land decisions in relation to the protection of the natural and cultural heritage of the Eastern Mediterranean area.

\subsection{Pre-Assessment Phase}

Building on the results from the Landscape Character Assessment was a key point in our strategy, which integrates results of level 1 and level 2 LCA assessments in the hazard analysis and landscape value analysis, respectively.

Prior to reaching the final model an assessment of the availability of material was conducted between the partners, discussions took place, and questionnaires were handed out. Partners were asked to share their opinions and expertise on the most pressing threats to the character of the landscape in 
the East Mediterranean region and on the landscape value appraisal methods. This formulated the basis on which the conceptual model was developed. Data collation then followed and continued in parallel with the development and refinement of the Risk Assessment model. The process included a back and forth interaction between the partners and the Lebanese team, through Skype and email, where discussions on data availability, coherence, and verification took place in order to achieve a comprehensive and homogeneous methodology. Limitations of available data led us to a further refinement of the model to suit the situations observed in the four partner countries.

\subsection{Risk Appraisal Phase}

\subsubsection{Landscape Hazard Identification}

Landscape hazard appears to be a more uncertain and less explored issue, where approaches have focused on the visual impact of changes in land-use due to human activities, such as the construction of new buildings or infrastructure [33,34]. Antrop [35] has focused on four different categories of pressures on landscapes that can be strictly interrelated: housing and settlements, land as production space, infrastructure, and the use of land as recreation and fragmentation. In the MedScapes work, hazards were defined as potential threats that are likely to cause damage to the landscape character in the event that they occur [24]. The landscape hazards were chosen according to the following criterion: severity in terms of the effect of the occurrence at a location (site parameter), applicability across the partner countries, availability of information, and relevance to results from the Landscape Character Assessment (LCA). Research on the most pressing threats to the Mediterranean countries, data entry on the most pressing threats per LDU, and discussions with the partners of the MedScapes project yielded the following list of hazards to be assessed: Desertification, Erosion, Forest Fires, and Intensification of Urban Sprawl Patterns. The partners ranked the hazards as per the following Table 1. Hazards ranking table, in which the value 6 represents the bigger perceived threat and 0 being the least.

Table 1. Hazards ranking table.

\begin{tabular}{cccccccc}
\hline Hazard & $\begin{array}{c}\text { Jordan } \\
\text { Yarmuk }\end{array}$ & $\begin{array}{c}\text { Jordan } \\
\text { Mujib }\end{array}$ & Cyprus & $\begin{array}{c}\text { Greece } \\
\text { Lesvos }\end{array}$ & $\begin{array}{c}\text { Greece } \\
\text { Epirus }\end{array}$ & Lebanon Total \\
\hline Intensification of urban sprawl & 6 & 0 & 5 & 6 & 5 & 6 & 28 \\
patterns & 5 & 0 & 3 & 5 & 6 & 5 & 24 \\
Erosion & 4 & 4 & 4 & 4 & 4 & 4 & 24 \\
Desertification & 3 & 5 & 2 & 0 & 2 & 3 & 15 \\
Loss of agricultural lands & 1 & 0 & 1 & 3 & 1 & 2 & 8 \\
Forest fires & 2 & 6 & 6 & 0 & 3 & 1 & 18 \\
Landscape transformation by & 0 & 0 & 0 & 0 & 0 & 0 & 0 \\
new planned developments & Flood & & & & &
\end{tabular}

Based on LCA data, and research on the most pressing threats on the Eastern Mediterranean landscape, four types of quasi-natural and man-made hazards where chosen:

- Desertification (qualitatively assessed)

- Erosion, (qualitatively assessed)

- Forest Fires (qualitatively assessed), and

- Intensification of urban sprawl patterns (quantitatively assessed)

\subsubsection{Landscape Hazards Ranking and Assessment}

Hazard assessment is the key element of risk analysis. It is carried out by processing info taken from different kinds of maps and/or field-work. In our research the evaluation was conducted at the level of the LDUs and the hazard rating was carried out using the related GIS maps (Erosion, Forest fire, 
Desertification, and Intensification of urban sprawl) and data provided by the project's partners based on their availability. The magnitude of the risk per each of the LDUs was identified and ranked using the qualitative classification with a score ranking from 1 (minimum hazard) to 4 (maximum hazard) as per Figure 4.

Geo-referencing data

\section{Overlaying LDUs}

Data extraction per LDU

Data input into GIS

Hazard intensity and location data

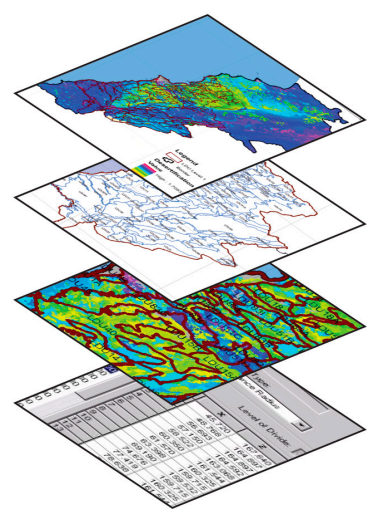

Value ranges used unanimously:

$\begin{array}{ccc}\text { Rank } & \text { Value } & \text { Value Range } \\ 1 & \text { Low } & 0-25 \\ 2 & \text { Low-Medium } & 25.1-50 \\ 3 & \text { Medium-High } & 50.1-75 \\ 4 & \text { High } & 75.1-100\end{array}$

Figure 4. Hazard assessment methodology. LDU, landscape descriptive unit.

The Intensification of Urban Sprawl Patterns was the only hazard that we were able to quantitatively assess using four parameters: existing settlement, landform, geology/slope, and informal settlements. The above were selected based on a study by La Rosa and Martinico in Sicily, Italy [24]. The criteria chosen to weight the parameters emphasized the importance of existing settlement patterns and geology/slope, with weights of $40 \%$ and $30 \%$, respectively. We assigned lower weights for landform $(20 \%)$ and informal settlements $(10 \%)$ since their assessment is based on the existing trends of settlement/landform and the large influx of refugees. The data used includes: the spatial data from the Landscape Character Assessment, which was indexed based on current trends and on relationships between attributes; as well as the United Nations High Commissioner for Refugees (UNHCR) map of Syrian refugee camp locations, which were considered for the assessment of the impact of informal settlements on intensification patterns. In Lebanon, the large influx of refugees has played a role in altering the landscape in key areas such as the Bekaa Valley, Coastal South Lebanon, and North Lebanon. The assessment and ranking methodology is shown in Table 2. 
Table 2. Intensification of Urban sprawl: Assessment and ranking.

\begin{tabular}{|c|c|c|c|c|c|c|c|c|c|c|c|c|}
\hline Attribute & & & & & & & & & & & Formula & $\begin{array}{l}\text { Total } \\
\text { Value }\end{array}$ \\
\hline LANDFORM & water body & deep valley & mountainous areas & valley & high uplands & uplands & high plateau & hills & plateau & Low lands & $100 / 6 \mathrm{X}$ & \\
\hline RANK & 0 & 0 & 1 & 2 & 2 & 3 & 4 & 4 & 5 & 6 & RANK & $20 \%$ \\
\hline SETTLEMENT & Unsettled & Sparsely Settled & $\begin{array}{l}\text { Settled-Medium } \\
\text { Spaced }\end{array}$ & $\begin{array}{l}\text { Settled-Closely } \\
\text { Spaced }\end{array}$ & Settled & Settled to Urban & Urban & & & & $100 / 4 X$ & $40^{\circ}$ \\
\hline RANK & 1 & 2 & 3 & 4 & 0 & 0 & 0 & & & & RANK & \\
\hline $\begin{array}{l}\text { INFORMAL } \\
\text { SETTLEMENTS }\end{array}$ & Unsettled & Sparsely Settled & $\begin{array}{l}\text { Settled-Medium } \\
\text { Spaced }\end{array}$ & $\begin{array}{l}\text { Settled-Closely } \\
\text { Spaced }\end{array}$ & Settled & Settled to Urban & Urban & & & & $100 / 4 X$ & $10 \%$ \\
\hline RANK & 4 & 3 & $\begin{array}{c}\text { spaceu } \\
2\end{array}$ & $\begin{array}{l}\text { spaced } \\
1\end{array}$ & 0 & 0 & 0 & & & & RANK & $10 \%$ \\
\hline GEOLOGY/SLOPE & No Risk & Low & Medium & High & & & & & & & & \\
\hline RANK & 3 & 2 & 1 & 0 & & & & & & & & \\
\hline GEOLOGY & Limestone & Sandstone & Chalk & Bare Rock & Alluvials & Marl & Volcanics & Shales & Fluvials & & $100 / 3 X$ & \\
\hline RANK & 1 & 2 & 3 & 4 & 5 & 6 & 7 & 8 & 9 & & RANK & $30 \%$ \\
\hline SLOPE \% Range & 0 & $1-12$ & $13-20$ & $21-35$ & $36-50$ & $51+$ & & & & & & \\
\hline RANK & 6 & 5 & 4 & 3 & 2 & 1 & & & & & & \\
\hline
\end{tabular}




\subsubsection{Landscape Value Identification}

The authors of this study distinguish between landscape value and landscape character. Landscape character is concerned with the fabric that makes up the landscape of a place, usually in the absence of qualitative rating system, but also with how that landscape is perceived (e.g., the pattern of available viewing, Williamson, 1979 [36]). Value, on the other hand, is concerned with the quality of experience of place, associated in the literature with as diverse themes as visual variety (Leonard and Hammond, 1984 [37]), positive emotions (Daniel and Vining, 1983 [38]), and length of association with a landscape (RFA, 2002 [39]).

Values in landscape have been studied by numerous researchers in a variety of contexts [40]: Greg Brown and colleagues have, for example, undertaken extensive work in defining landscape values for participatory mapping [41-43]; Michael Jones has developed a categorization of values for addressing conflicts in planning issues [44]; Janet Stephenson has exposed how different forms of assessments take up certain landscape values whilst ignoring others [45]; while others have taken up the question of how professional values differ from those of laypersons professional contra lay person values [46]. Butler (2016), in particular, argues on how landscape character assessment represents a critical point in the framing of landscape values [40].

In our study, the landscape value was based on its physical character assessed throughout the LCA method implemented in the first phase of the MedScapes project considering the ecological and cultural qualities. To reach a comprehensive model that builds up on the LCA, integrates contemporary methods of evaluating the value of the landscape, and takes into account the expertise of the partner countries involved (Table 3). Partners' input), the following parameters were to be considered in the Landscape Value assessment:

a. Ecological Values (quantitatively assessed)

- Naturalness of habitat

- Habitat continuity

- Dominant habitat type

b. Historical/Cultural Values (quantitatively assessed)

- Archeological sites

- Heritage/historical entities, trails, centers and museums

Table 3. Partners' input.

\begin{tabular}{|c|c|}
\hline Greece & $\begin{array}{c}\text { Cultural values (architecture, traditional settlements, field patterns, terraces) } \\
\text { Environmental values (vegetation, geomorphology, fauna) } \\
\text { Historical values (archeological and monumental sites) } \\
\text { Economic values (agricultural, tourist) }\end{array}$ \\
\hline Cyprus & $\begin{array}{c}\text { Cultural Integrity (change of use, survival of cultural pattern, visual impact of change) } \\
\text { Ecological integrity (naturalness of LDU, habitat continuity, number of main habitat types, } \\
\text { dominant type, intensity of management) }\end{array}$ \\
\hline Jordan & $\begin{array}{c}\text { Geology } \\
\text { Natural Landforms } \\
\text { Vegetation } \\
\text { Fauna environment } \\
\text { Landscape diversity } \\
\text { Historical roads and town centers }\end{array}$ \\
\hline
\end{tabular}

\subsubsection{Landscape Value Assessment}

To assess the value of the landscape we analyzed and assessed data extracted from the LCA process, land cover and land-use maps, satellite imagery (which was an asset, considering the scale 
of the study), and historical/cultural maps produced by governmental institutions. The two main parameters were weighed at $80 \%$ (ecological integrity) and 20\% (historical/cultural values).

\section{Ecological Integrity}

Adhering to the LCA standards of the MedScapes project, Ecological Integrity was assessed based on the following components: habitat continuity, dominant habitat, and naturalness of LDU (Table 4).

Table 4. Ecological Integrity ranking method.

\begin{tabular}{|c|c|c|c|c|c|c|}
\hline & & & & & Value & $\begin{array}{c}\text { Total Value per } \\
\text { LDU/100 }\end{array}$ \\
\hline $\begin{array}{l}\text { Habitat } \\
\text { Continuity }\end{array}$ & Continuous & $\begin{array}{l}\text { Linked } \\
\text { Patches }\end{array}$ & $\begin{array}{l}\text { Separate } \\
\text { Patches }\end{array}$ & Fragmented & $/ 4$ & value/4 \\
\hline \multirow[t]{2}{*}{ Rank } & 4 & 3 & 2 & 1 & & \\
\hline & & & & & & + \\
\hline \multirow{3}{*}{$\begin{array}{l}\text { Habitat Type } \\
\text { Rank }\end{array}$} & Herbaceous & Low Scrub & Tall Scrub & \multirow{3}{*}{$\begin{array}{cc}\text { Woodland } & \text { Cultivation } \\
4 & 2 \\
\end{array}$} & & \\
\hline & 1 & 2 & 3 & & 14 & Value/4 \\
\hline & & & & & & + \\
\hline $\begin{array}{c}\text { Naturalness } \\
\text { of LDU }\end{array}$ & $\begin{array}{l}\text { Mostly } \\
\text { natural }\end{array}$ & $\begin{array}{l}\text { Semi } \\
\text { Natural }\end{array}$ & Even Mix & $\begin{array}{c}\text { Mostly } \\
\text { cultivated }\end{array}$ & & \\
\hline \multirow[t]{3}{*}{ Rank } & 4 & 1 & 3 & 2 & $/ 4$ & Value/4 \\
\hline & & & & & & $=$ \\
\hline & & & & & Total/12 & $\begin{array}{c}\text { Cumm. Total/12 } \\
\times 100\end{array}$ \\
\hline
\end{tabular}

\section{Habitat Continuity $(33.33 \%)$}

This assessment was carried out per LDUs by relying on high-resolution satellite imageries. A continuous landscape (rank 4) was the most valuable type, as characterized by being an uninterrupted patch with few construction/road networks, quarries, etc.; whilst a fragmented landscape (rank 1) was the least valuable type, marked by heavy urbanization and land-reshaping activities (Figure 5).
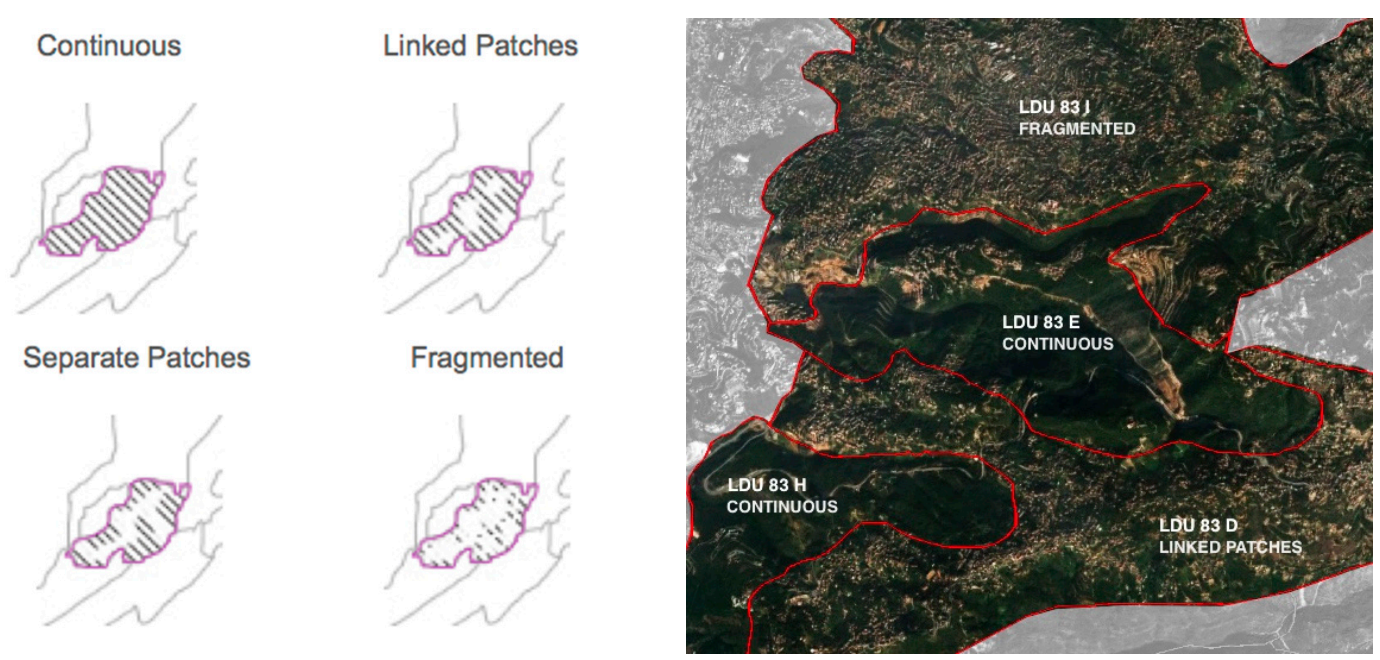

Figure 5. Habitat Continuity assessment per LDUs. 
Dominant Habitat (33.33\%)

The data were derived from land cover and land-use maps, taking into consideration the most dominant habitat type per LDU. Table 5 below reports the ranking system of each type and related description.

Table 5. Dominant habitat ranking system of each landscape type.

\begin{tabular}{cccc}
\hline Dominant Habitat & Type & Rank & Description \\
\hline Herbaceous & $<0.2 \mathrm{~m}$ & 1 & Natural grasslands, rocky landscapes, bare rocks. \\
Low Scrub & 0.2 to $1 \mathrm{~m}$ & 2 & Sclerophyllus beg. \\
Cultivation & Field crops, orchards, groves & 2 & Groves, agriculture, cultivation patterns. \\
Tall Scrub & $0.5 \mathrm{~m}$ to $1.5 \mathrm{~m}$ & 3 & Transitional woodland-shrub. \\
Woodland & $1.2 \mathrm{~m}$ & 4 & Forests (coniferous, broad leaved). \\
\hline
\end{tabular}

Naturalness $(33.33 \%)$

LDUs were categorized according to their naturalness, as shown in Table 6 below. As most landscapes had a mosaic of land-use types, this classification differentiates between landscapes that are minimally altered (mostly natural, rank 4), and landscapes that are mostly built up with still existing cultivation practices (semi-natural, rank 1) (Figures 6 and 7).

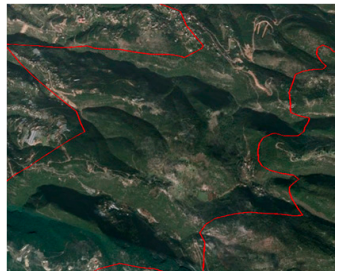

(a)

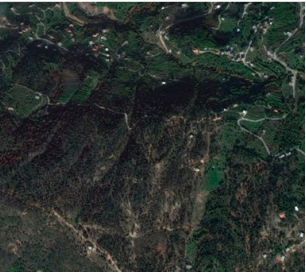

(b)

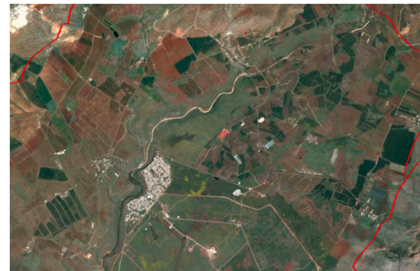

(c)

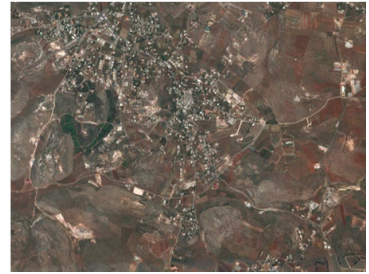

(d)

Figure 6. Naturalness rank per each of the LDUs: (a) Mostly Natural, (b) Even Mix, (c) Mostly Cultivated and (d) Semi-Natural.

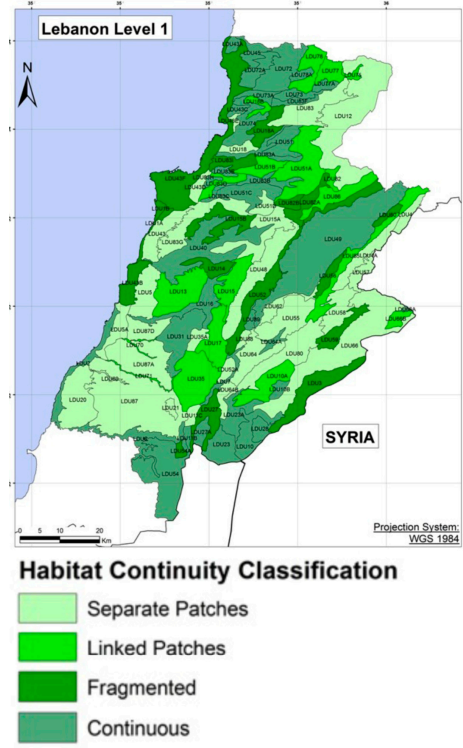

(a)

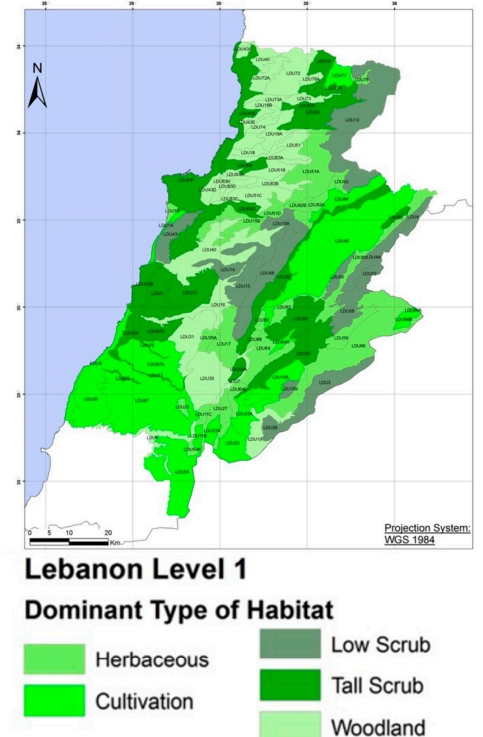

(b)

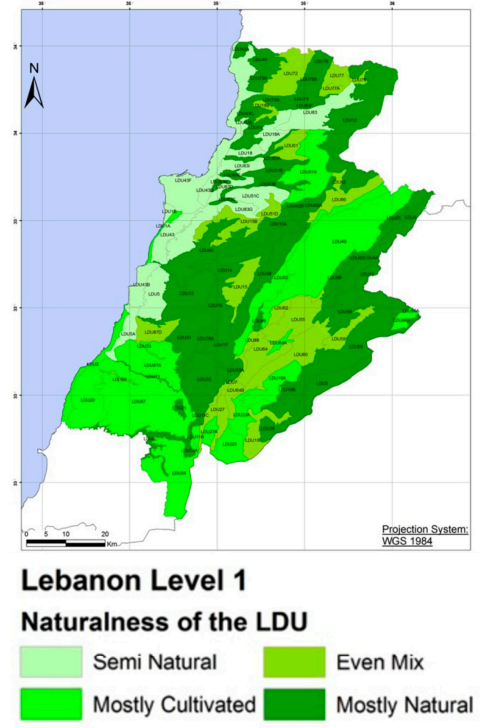

(c)

Figure 7. Maps of Lebanon's habitat continuity (a), dominant habitat (b), and naturalness (c). 
Table 6. Ranking system of LDUs according to naturalness.

\begin{tabular}{ccc}
\hline Naturalness & Rank & Description \\
\hline Mostly Natural & 4 & A mostly natural LDU \\
Even Mix & 3 & A mix between a natural and cultivated LDU \\
Mostly Cultivated & 2 & Mostly agricultural field crops, orchards, groves, terraces \\
Semi Natural & 1 & A mix of unnatural and cultivated LDUs \\
\hline
\end{tabular}

\subsubsection{Historical/Cultural Values}

Cultural identity is strongly associated with the ways in which people interact with their landscapes. Much has been written about the significance of landscape (or the related idea of place) to communities and their cultural identity [47]. The literature ranges from sociological and anthropological work, to studies of place identities [48,49]. In our study, cultural values are assessed using the national maps and by ranking the data extracted from them based on the importance of the site/monument, on the dimension of the area/architecture, and on the regional and national significance. Two components were taken into consideration: Archeological sites, and Heritage/historical entities (trails, centers, museums, etc.). The assessment was quantitatively conducted considering the availability of spatial data.

\subsection{The Judgment/Risk Evaluation Phase}

The Risk Evaluation was conducted by determining the significance of the estimated risks in relation to the loss of the assessed Landscape Values by applying the MEDSCAPES risk equation:

$$
\text { Risk }=\text { Hazard } \times \text { Landscape Value }
$$

which was derived from the original equation we borrow from the EU project ARMONIA [21]:

$$
\text { Risk }=\text { Hazard } \times \text { Expected losses }
$$

where Expected losses is Vulnerability per Value.

In our approach, expressed by the above equation, Hazard is a potential threat that is likely to cause damage to the character of the landscape in cases where it occurs, and Landscape Value (LV) is the value of the assets in each Landscape Descriptive Unit (LDU), mainly being ecological, natural, and historical/archeological assets. The equation was portrayed through a two-dimensional matrix that we drew based on a study Greiving et al. performed on Integrated Risk Assessment of Spatially Relevant Hazards [50]. The same authors, having in mind the cost-benefit analysis in relation to the economic and physical risk, developed a similar matrix during the ARMONIA project. In the $4 \times 4$ matrix the hazard intensity and the LV degree were summed up to yield the integrated risk value. It was represented through a color code that identifies the risk classes from very low risk to very high risk (Figure 8). This tool also acts as a legend for the produced Landscape Risk Maps by decoding the value of the risks in each LDU as portrayed in the maps. 


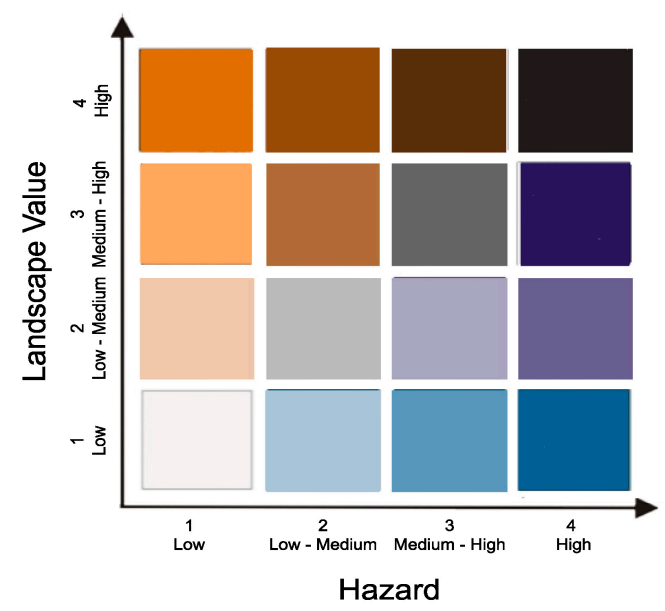

(a)

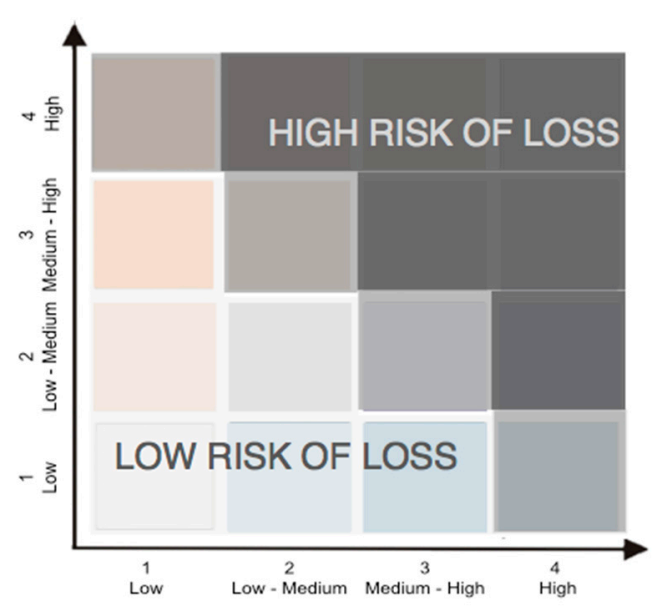

(b)

Figure 8. MEDSCAPES risk assessment (LRA) matrix: (a): Color code legend of the LRA; (b): Dark colors $=$ High risk of loss, Light colors = low risk of loss.

\subsection{The Risk Management Phase: Landscape Decision Support System (LDSS)}

The Decision Support System is defined as a computer aided system to support decision-making, assisting stakeholders in comparative assessment and selection of options for change. It aids in scenario alteration and generation to support future decisions. Spatial Decision Support Systems (SDSSs) for natural resources management are computer-based tools that tightly integrate decision theory and models with ecological models and GIS analyses and mapping [51]. The information provided by SDSSs gives decision makers increased ability to follow outcomes of interacting variables, improves the reproducibility of decisions, and documents the reason why a particular choice was made [21]. The use of SDSSs in land-use and urban planning is a common approach in Western countries [52], but its application in the spatial planning of the East Mediterranean region is still not valued.

Planning is a future oriented activity and the future being planned for is always more or less uncertain. Nevertheless, an image of what the future may look like in important aspects is needed in order to provide a context for the actions considered for inclusion in the plan. For planning purposes most of the examples of SDSSs have been calibrated for the regional scale in a very case-specific way for solving one, or only few, functional problem(s) [53]; for example, for coastal zone management [54] and for monitoring purposes [55]. Advances have been made in the use of spatial models to assess the impact of potential development [56].

The tool proposed in MedScapes offers an integrative framework in landscape risk assessment and scenario building for the support of land-use decisions. It is map-centered and scenarios are spatially assessed. The use of a LDSS aims at helping stakeholders to spatially visualize future possibilities and alternatives to support their decisions.

Generally, the decision-making problems can be categorized under certainty conditions or under uncertainty conditions, according to the amount and typology of knowledge available to the Decision Making (DM) [57]. Due to the limited information available in the four partner countries and the difficulties encountered in collecting, comparing, and estimating data from different resources the problem description and analysis were conducted under uncertainty conditions.

The Landscape Decision Support System in MedScapes was developed as an interactive web-based interface that serves to implement the LRA approach while managing the input data. It provides LCA, Hazards, Landscape Values, Risk, and Scenarios maps for the identification and prioritization of areas, and the basis for the definition of adaptation and planning strategies and measurers. Through the LDSS the user can visualize the results of the Landscape Character Assessment, 
the Landscape Risk Assessment process and create spatially-based scenarios by altering the hazard pertaining to intensification of urban sprawl patterns and the Landscape Value (Figure 9).

It has the following key features:

- It maps and visualizes information on up to four different hazards and the consequent losses on Landscape Value at the scale of the LCA level 1 assessment (1:250,000 scale).

- It enables different scenarios to be run which generate information about hazards and landscape loss for all the study areas in the four partners countries and for each of the LDUs, so that different options for mitigating risks or developing land can be compared

- It enables editing scenarios by altering different indexing weights and LDU ranks

- It provides a knowledge base on hazards

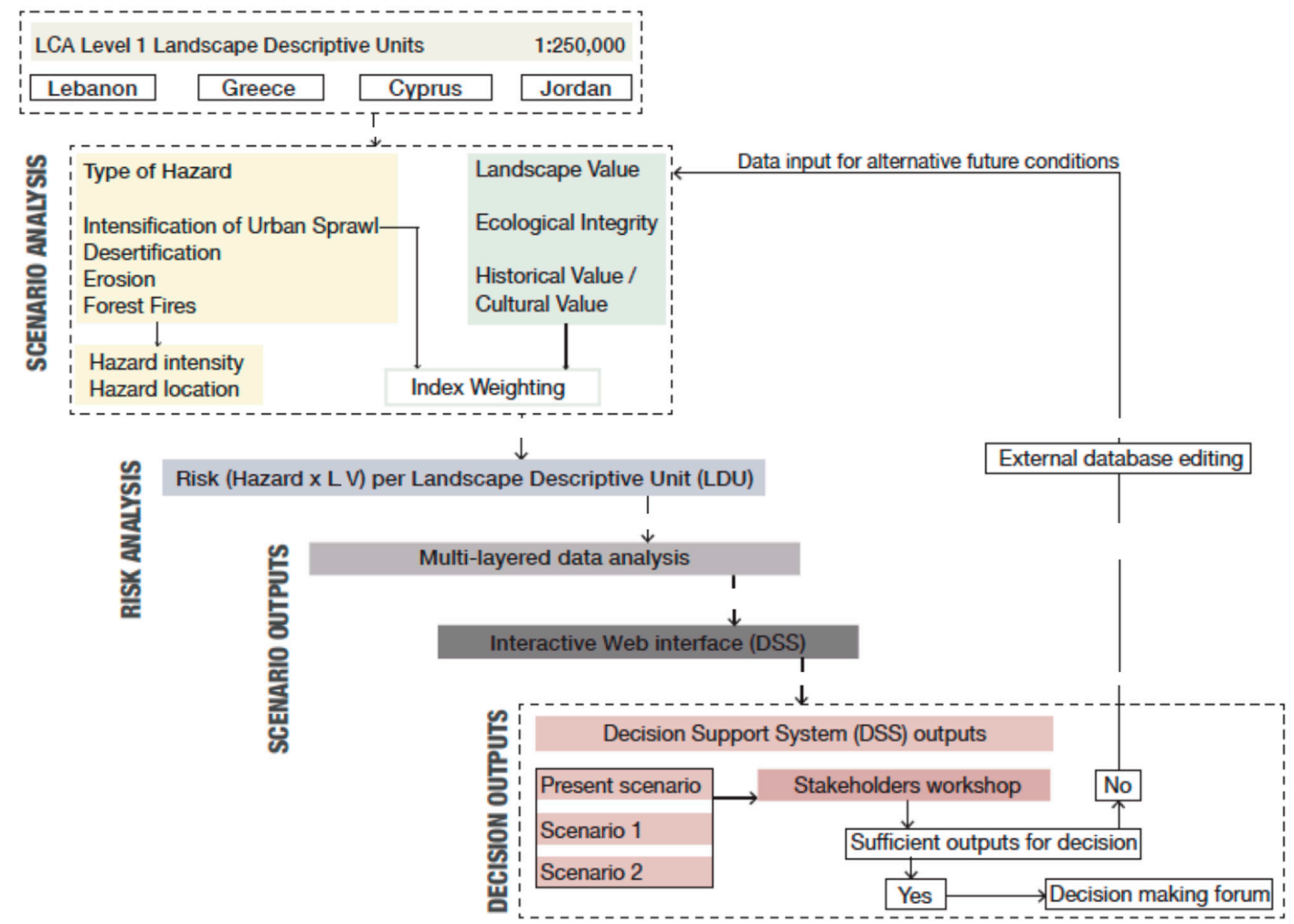

Figure 9. Methodology: from Risk Assessment to Decision Support System. LCA, Landscape Character Attribute; LV, Landscape Value.

The LDSS does not require the end user to have any knowledge or experience in LCA. It is embedded in a user-friendly GIS application where the LCA and LRA parameters cannot be edited by the users but only by experienced and well-trained personnel inside the ministries or regional and local planning offices.

The LDSS offers an integrative framework in landscape risk assessment and scenario building for the support of land-use decisions via a map-centered approach. It informs decision-makers about the risks affecting the land and thus will allow stakeholders to use real scenarios when determining new mitigation, conservation, restoration, or prevention measures. In environmental studies, the Intergovernmental Panel on Climate Change (IPCG) scenarios are described as 'images of the future, or alternative futures' that are neither predictions nor forecasts, but an alternative image of how the future might unfold [58].

MEDSCAPES Scenario Generator (SG) has been developed with the following capabilities:

- Credible scenarios are translated into changes on the GIS map. 
- The SG queries the user for the appropriate information.

- The scenario(s) are then processed through the model.

The most important value of the LDSS lies in its capacity to easily communicate the results of the LCA and RA to a large and diverse audience through the scenarios' maps and for its interactivity which thus gives users the possibility to manipulate the data and spatially visualize the related scenarios. The most important function of the scenarios is that they act as crucial bridges between environmental/landscape science and policy. They influence policymaking by summarizing and synthesizing scientific knowledge in a form that can be used by policymakers to develop policies [55].

\section{LDSS Functionality}

The LDSS consists of a database, spatial analysis and bi-dimensional visualization of LCA and risk maps, Graphical User Interface (GUI), and a simulation model. The database supports cartographic info and permit the users to build spatial relations between coordinates and attributes. It contains landscape parameters that are related to the selected study areas for each of the four partner countries (i.e., Landforms, Soils, Land-cover, LCT, Erosion, Forest fire, Settlement, etc.), and coordinates for LDU polygons that allowed the partner countries to be segmented into the assessed LDUs. The spatial analysis and bi-dimensional visualization of risk maps enable the user to interactively explore two-dimensional LCA, hazards, landscape values, and risk maps in the selected areas of the four East Mediterranean partner countries. The GUI facilitates the interaction of the final user with the system. The simulation model permits the user to spatially create scenarios by rank modification or weight modification. The tool and the GUI closely follow the conceptual model of the LRA, enabling the user to perform the step by step assessment, varying input parameters, testing and comparing different combinations of scenarios.

The user interface is designed in a way to easily allow users to interact, create, and visualize through maps the result(s) of their choice(s).

\section{Results}

The above-described methodology was first tested on Lebanon's study area. This trial and error period clarified what kind of data would be specifically needed from the partner countries, and the different limitations faced. The concept of the model was then shared in phases of its development with the partners, where Skype meetings took place to share views on the model and the requested data. The final model reflects the difficulties encountered and the necessity to develop a system able to use and process such diversified information and to produce comparable results. Once the methodology had been built the expectation was to adopt it in the different countries and to further develop it to better respond and fit to the countries' planning rules and logic. In any case, it was a trial to consider the landscape, and the relevance that it is acquiring all over the world, with the definition of hazards and typology/aim of risk management.

\subsection{Hazard Maps}

Desertification, Erosion, Forest Fire, and Intensification of urban sprawl hazard maps were produced for all of Cyprus and for the selected area of Lebanon. In Greece and Jordan, Forest Fire was not assessed due the impossibility of getting the right information to be reworked. Furthermore, while the Desertification, Erosion, and Forest Fire hazards arise from different sources of stressors that were not assessed during the length of the MedScapes project, the final outcome is the result of data collected and compared using the available forms of national information that were reworked and qualitatively ranked due the uncertainty of the materials (Figures 10-13). 


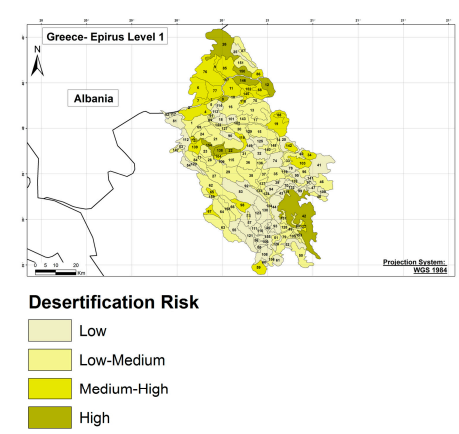

(a)
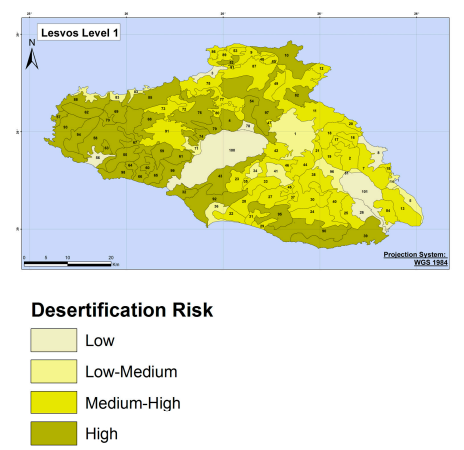

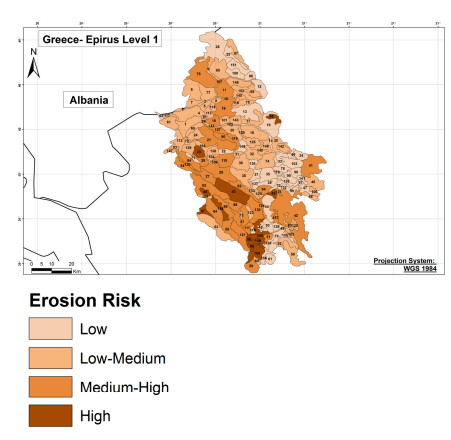

(b)

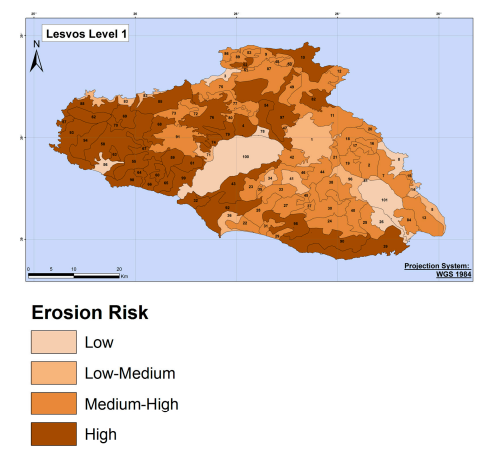

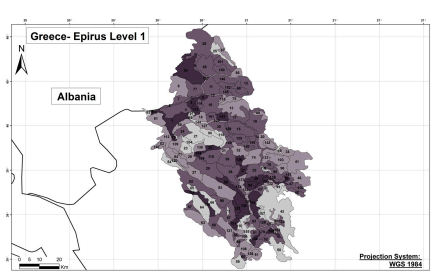

Risk of Intensification of Urban Sprawl Patterns

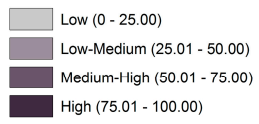

(c)

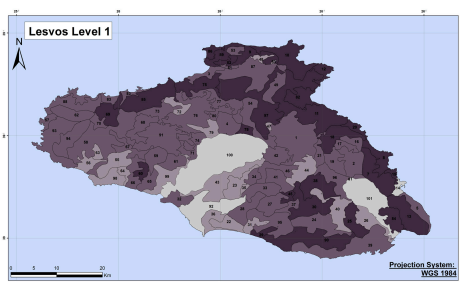

Risk of Intensification of Urban Sprawl Patterns $\square$ Low (0 - 25.00)

Low-Medium (25.01 - 50.00)

Medium-High (50.01 - 75.00)

High $(75.01$ - 100.00)

(d)

(e)

(f)

Figure 10. Hazard Maps for LDU's of Desertification (left), Erosion (middle), and Intensification of urban sprawl (right) in Greece: Epirus (a-c) and Lesvos (d-f).

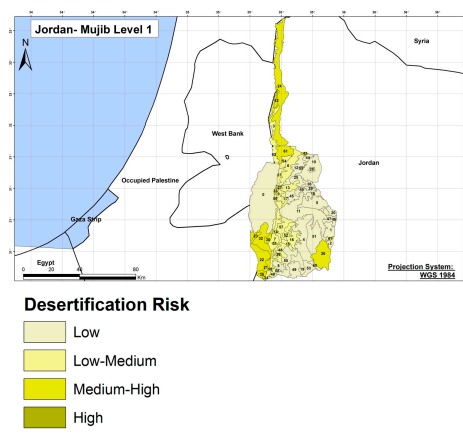

(a)

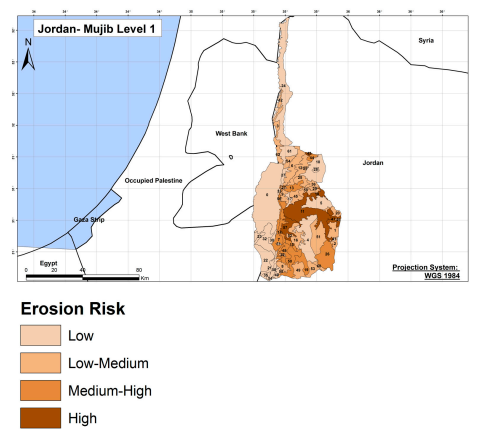

(b)

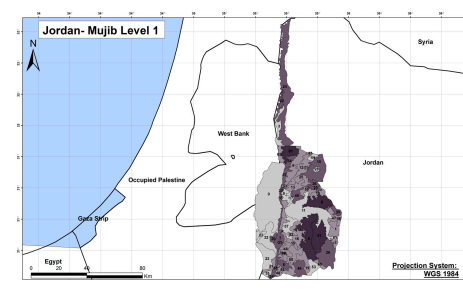

Risk of Intensification of Urban Sprawl Patterns Low $(0-25.00)$

Low-Medium (25.01 - 50.00)

Medium-High (50.01 - 75.00)

High (75.01 - 100.00)

(c)

Figure 11. Cont. 


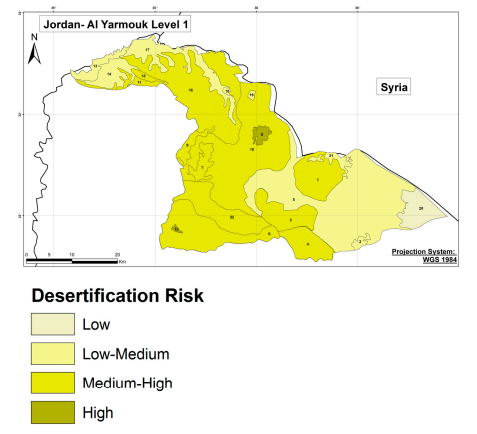

(d)

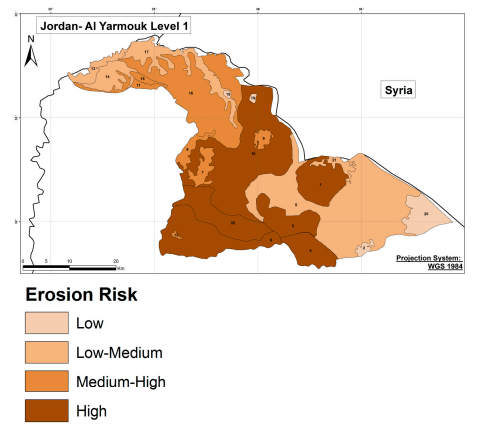

(e)

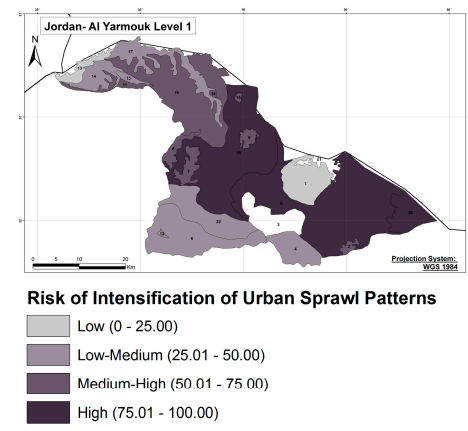

(f)

Figure 11. Hazard Maps for LDU's of Desertification (left), Erosion (middle), and Intensification of urban sprawl (right) in Jordan: Al-Yarmuk (a-c) and Mujib (d-f).

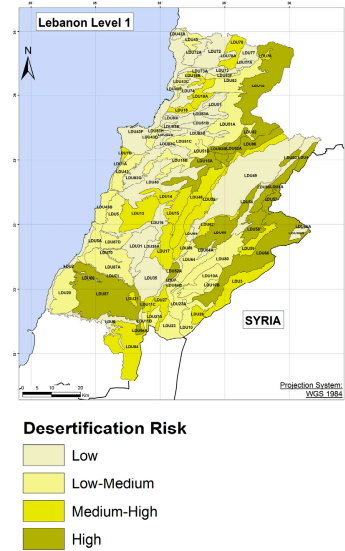

(a)

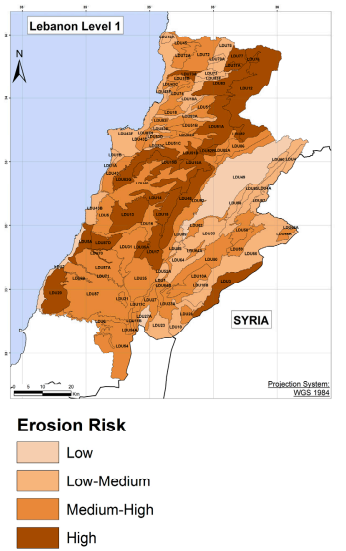

(b)

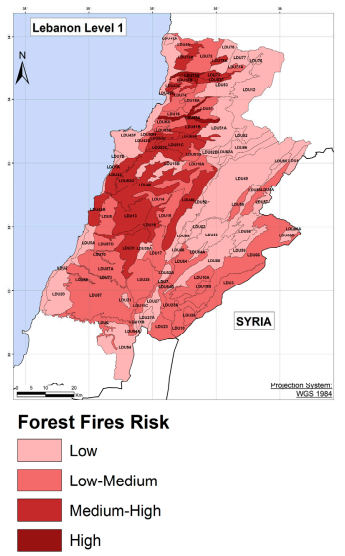

(c)

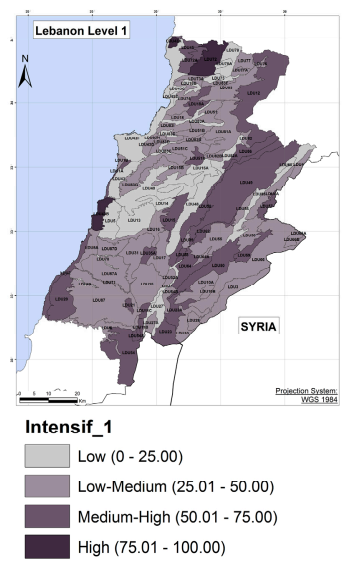

(d)

Figure 12. Hazard Maps for LDU's of Desertification (a), Erosion (b), Forest Fire (c), and Intensification of urban sprawl (d) in Lebanon.

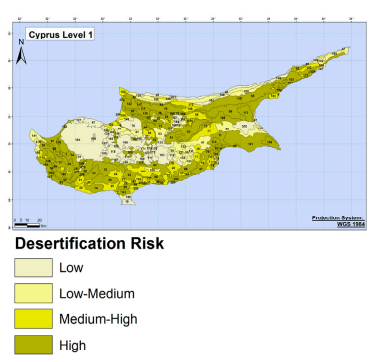

(a)

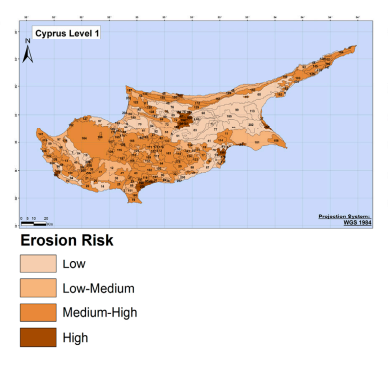

(b)

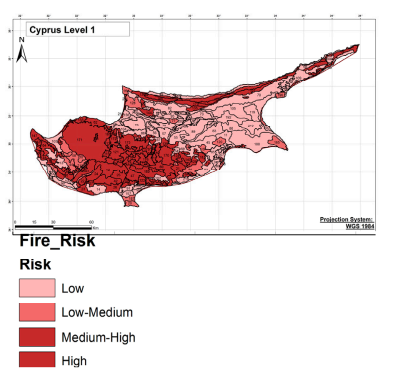

(c)

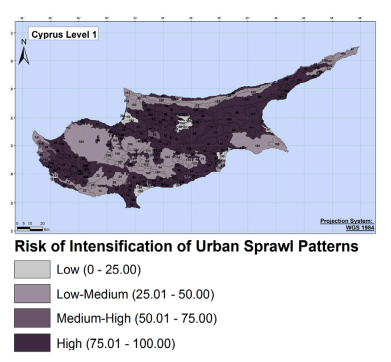

(d)

Figure 13. Hazard Maps for LDU's of Desertification (a), Erosion (b), Forest Fire (c), and Intensification of urban sprawl (d) in Cyprus.

\subsection{Landscape Value Maps}

At the end of the Landscape Value assessment we produced a LV map for all the selected areas for each partner's country (Figures 14-16). 


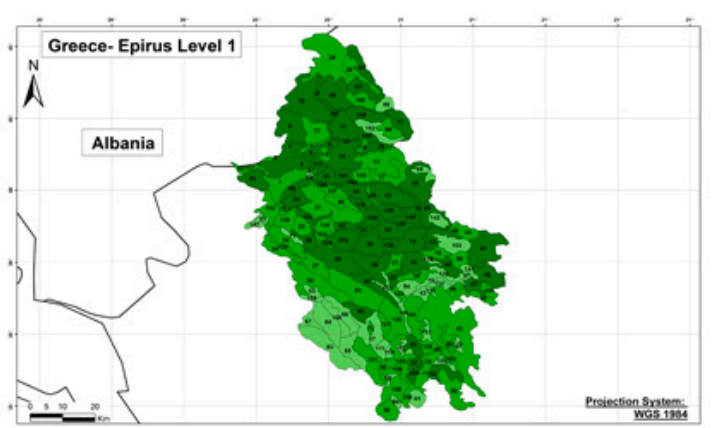

Landscape Value (In \%)

$\square$ Low (20.00 - 25.00)

Low-Medium (25.01 - 50.00)

Medium-High (50.01 - 75.00)

High (75.01 - 100.00)

(a)

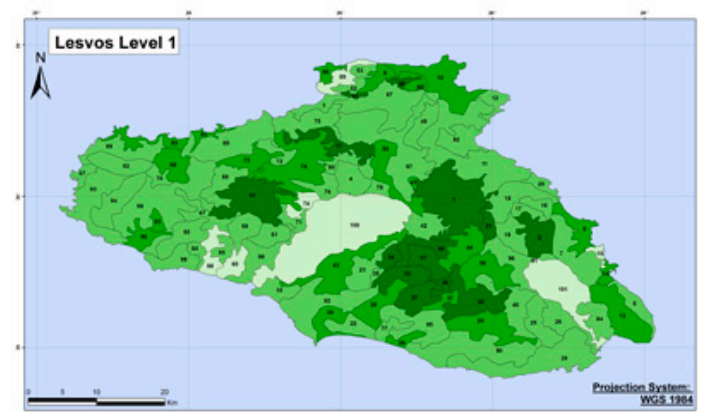

Landscape Value (In \%)

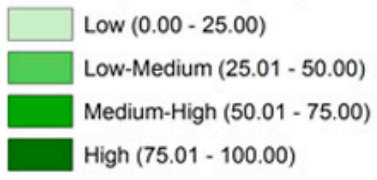

(b)

Figure 14. Landscape Value (LV) maps in Greece: (a) Epirus and (b) Lesvos.

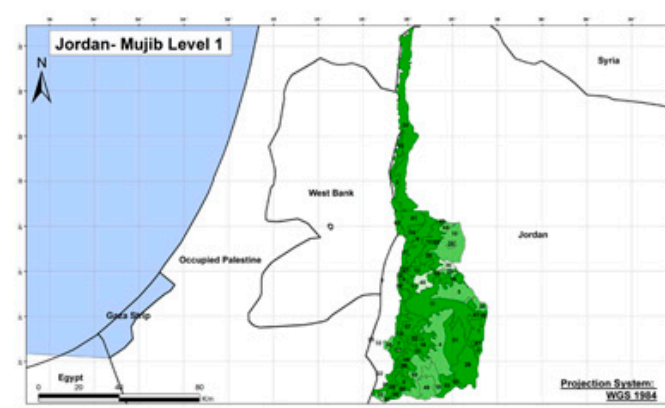

Landscape Value (In \%)

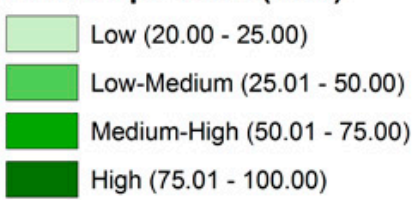

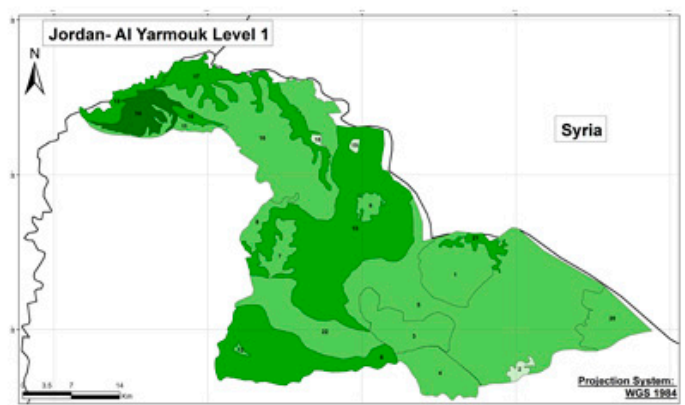

Landscape Value (In \%)

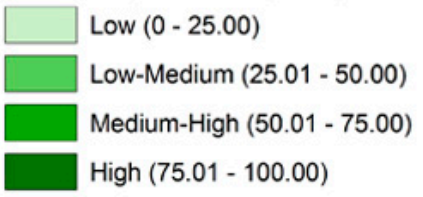

(b)

Figure 15. Landscape Value (LV) maps in Jordan: (a) Mujib and (b) Al-Yarmuk. 


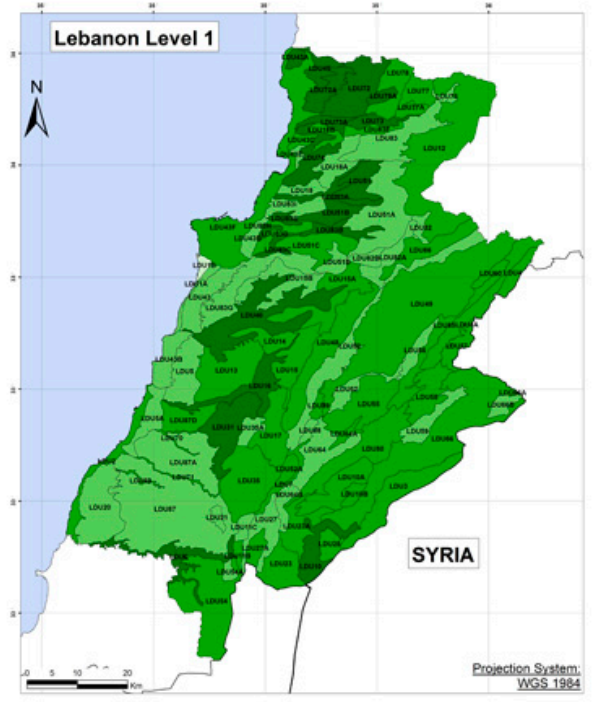

Landscape Value (In \%)

\begin{tabular}{|l}
\hline \\
$\square$ \\
\hline \\
Low $(0$ - 25.00) \\
Medium-High (50.01 - 75.00) \\
High (75.01 - 100.00)
\end{tabular}

(a)

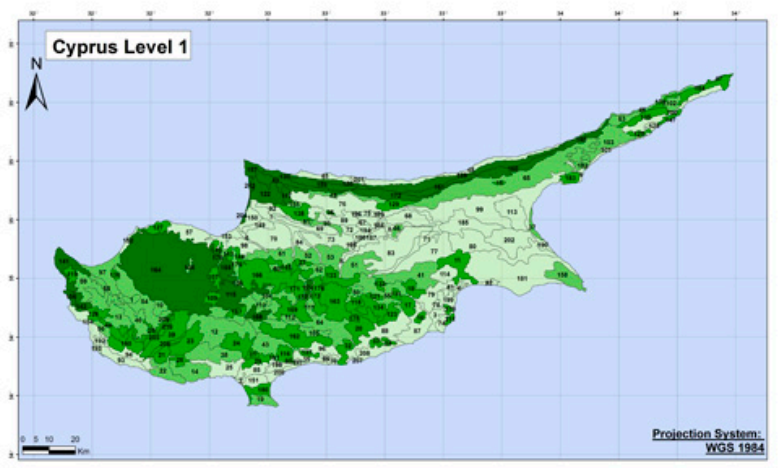

Landscape Value (In\%)

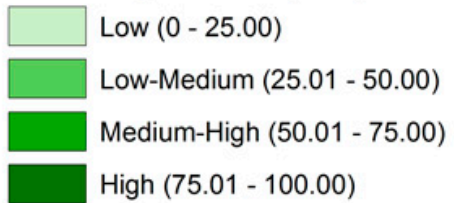

(b)

Figure 16. Landscape Value (LV) maps in (a) Lebanon and (b) Cyprus.

\subsection{Landscape Risk Maps}

The overall landscape risk maps produced within the LRA-LDSS are the result of the MedScapes risk equation that integrates hazard versus landscape value for the LDUs in the four analyzed countries: Cyprus, Jordan, Greece, and Lebanon (Figures 17-19).

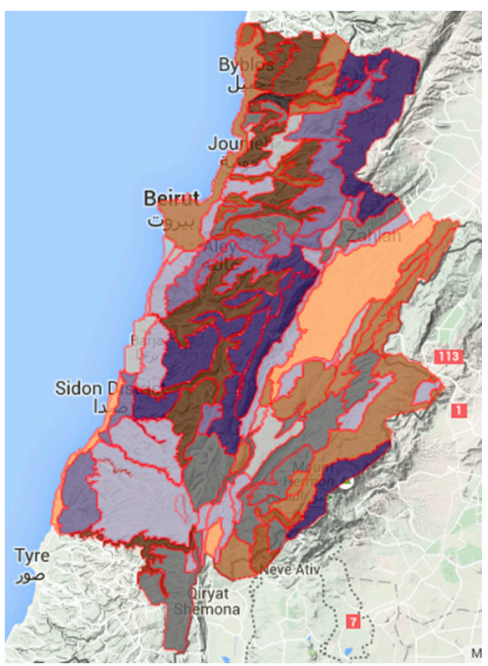

(a)

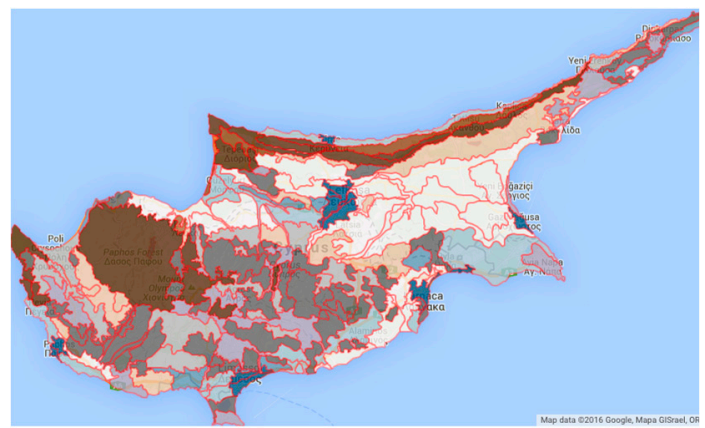

(b)

Figure 17. Landscape Risk Assessment (LRA) maps for Lebanon (a) and Cyprus (b). 


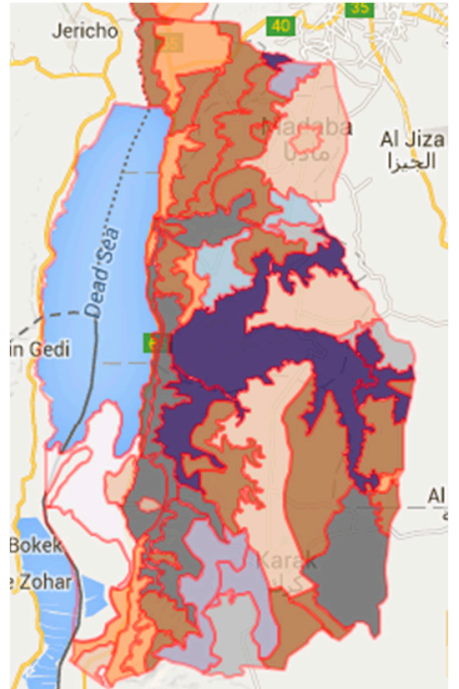

(a)

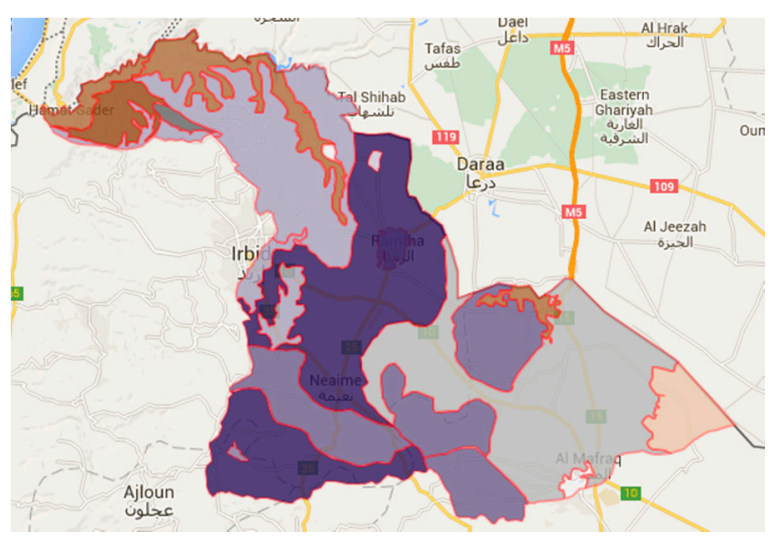

(b)

Figure 18. Landscape Risk Assessment (LRA) maps for the two areas in Jordan: $(\mathbf{a}, \mathbf{b})$.

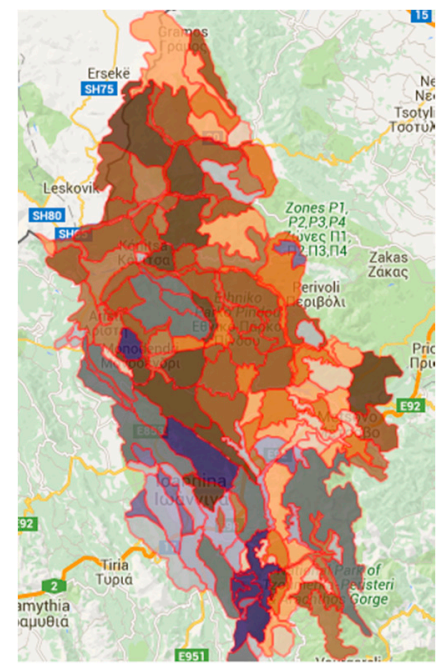

(a)

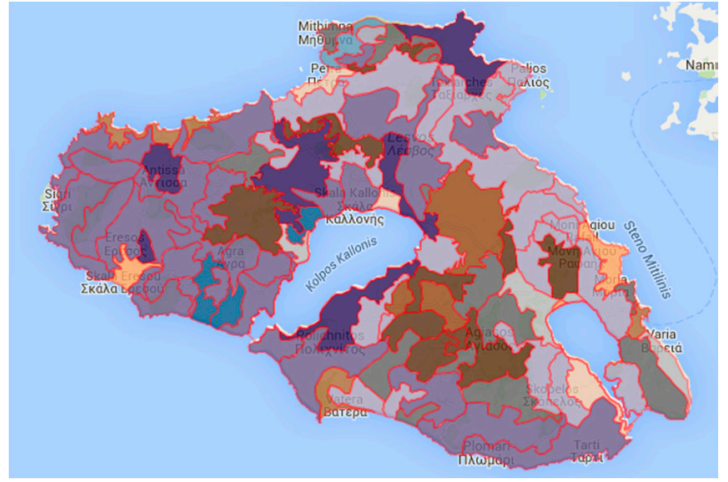

(b)

Figure 19. Landscape Risk Assessment (LRA) maps for the two areas in Greece: $(\mathbf{a}, \mathbf{b})$.

The two-dimensional matrix for a risk legend enabled us to spatially represent the results of our study (Figure 20). Furthermore, it plays an important role in the evaluation process of the effects of the risk in relation to the loss of landscape character of the affected area. For each chosen Hazard in every selected area, it enables us to estimate and judge the risk of a reduction in LV that is directly proportional to the intensity of the hazard. In the upper part of matrix, highlighted as 'high risk of loss', the dark colors detect the LDU's that are subjected to a greater risk. It means that they are areas of particular interest for protection/conservation land-use decisions, and indicates a more pressing need of attention. In Lebanon, $57.29 \%$ of LDUs lie within the high risk of loss zone, $31 \%$ lie within the medium risk of loss zone, and 9.79\% lie within the low risk of loss zone (Figure 21). 

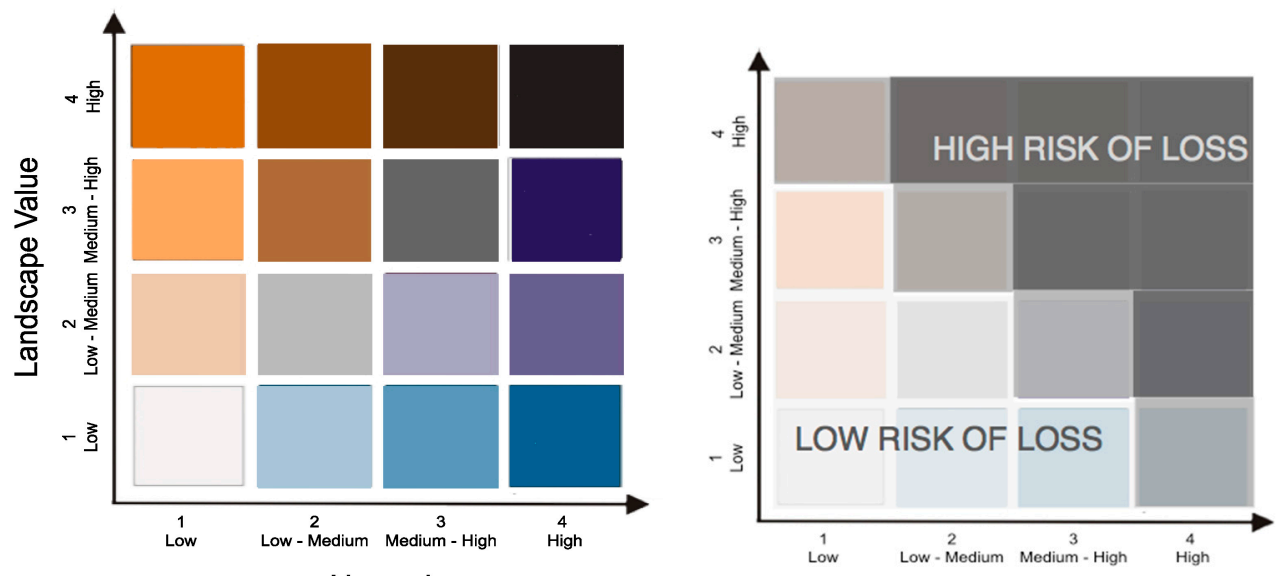

Hazard

Figure 20. Landscape Risk Assessment (LRA) legend.

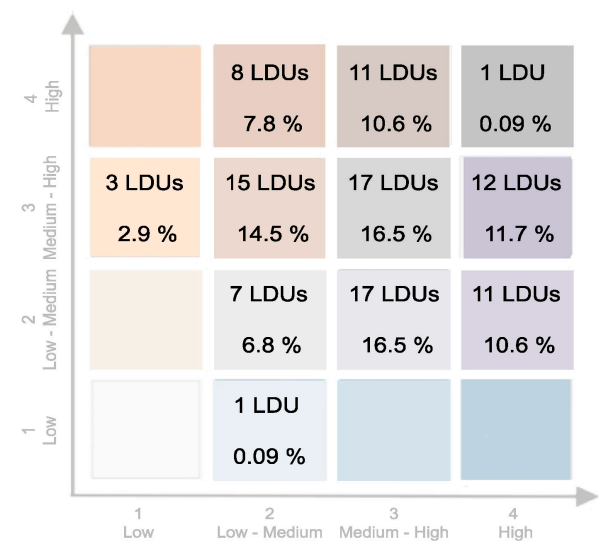

Figure 21. Number of LDUs per value of risk of loss of landscape value.

\subsection{Landscape Decision Support System}

The results of the spatial Risk Assessment are available online on the landscape RA and DSS interactive framework created during the MedScapes project. Using this tool, the users can visualize on GIS maps the outcome of the overall study and can generate spatially-based scenarios by altering the rank and weigh of the indicators. In the first case (Figure 22, the users can manipulate the Ecological Integrity components by changing the rank value of the Habitat Continuity, Dominant Habitat Type, and Naturalness and/or they can alter the Intensification of Urban Sprawl hazard components modifying the Refugees, Formation, Landform, and Settlement rank values. The operator can either start by filtering LDUs based on the indexing parameters, or by directly editing the LDUs of their choice, depending on their areas of interest. The higher the rank value assigned to the weighting of the parameter the more conducive it is to Landscape Value and Intensification of Urban Sprawl. 


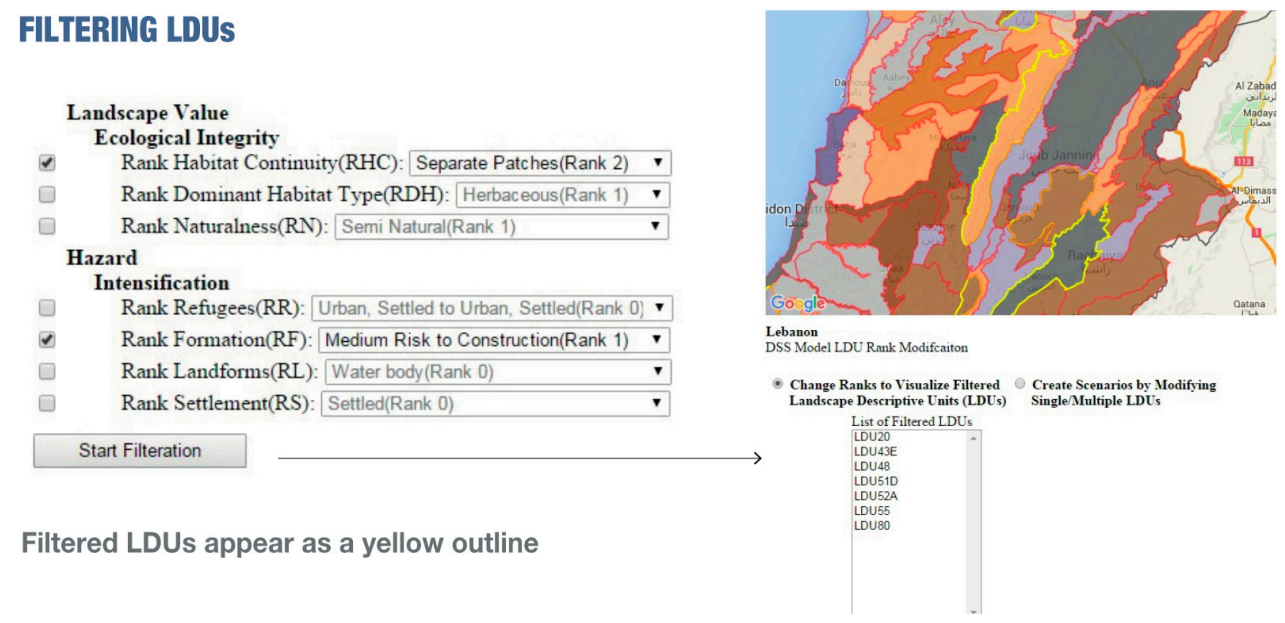

Figure 22. LDSS scenarios create by rank modification.

In the case of the scenarios generate by weight modification, the Landscape Values and Intensification of Urban Sprawl pressures could be changed bearing in mind that the total value of the weight percentage can't exceed the 100 percent (Figure 23). The scenarios generated by the model allow users to see a case series of possible physical transformations of the territory. Those changes, due to the modified intensity of the hazards and of the LV, will have repercussions on the character of the landscape that will be readable and evaluable with the help of the matrix. While identifying and ranking the LDU areas at greatest risk of loss of landscape character the scenarios will help decision-makers in choosing the needed measures and actions to reduce the exposure to the selected hazards.

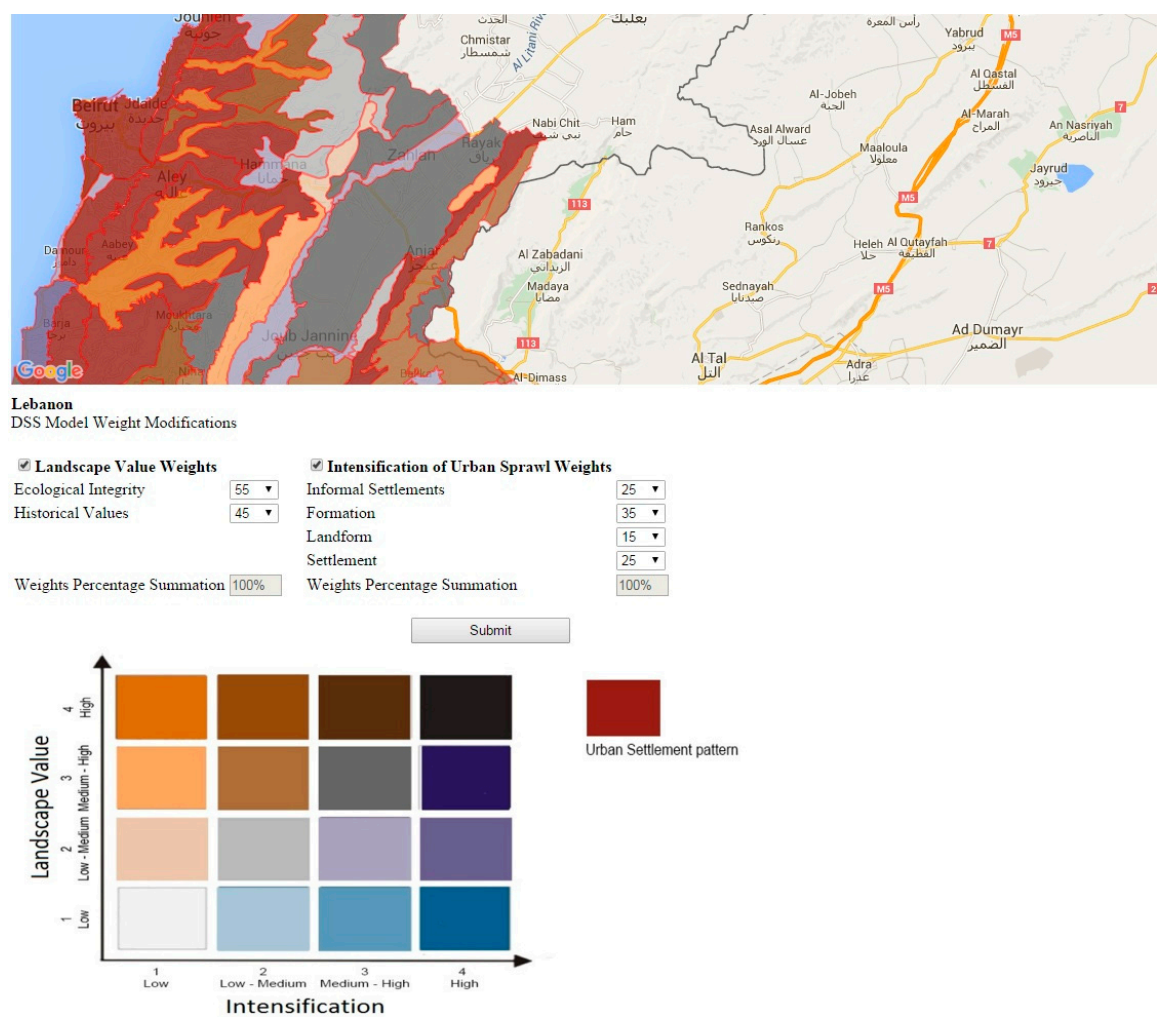

Figure 23. LDSS scenarios created by weigh modification. 


\section{Discussion}

The LRA LDSS model conceived for MEDSCAPES aimed to develop a tool that helps in the process of landscape decision-making for the protection of the natural and cultural heritage of the Eastern Mediterranean area. It was formulated by building on the Landscape Characterization procedure by relating/integrating its findings into the Landscape risk assessment within the framework of a decision support tool. This was a means of assisting administrators/stakeholders in the planning process through scenarios that were drawing modifying weight and rank of the indicators. The literature on LCA, RA, and DSS reveals that in the past decades different models have been built to facilitate the decision process, thus providing a basis for the definition of adaptation measures and planning strategies. A study by Frede et al. (2002) discusses sustainable planning through understanding multiple functions of the landscape, based on spatial analyses and assessments [59]. The MULBO model offers a framework of tools to integrate assessments of landscape functions into land use decision-making [21].

Ryan et al. (2006) discuss opportunities to involve stakeholder participation in land use decision problems for greenway planning applications [60]. Most of the SDSS or C-DSS models contemplate the inclusion of stakeholder participation, i.e., the Collaborative Multi-Criteria Spatial Decision Support System (C-MC SDSS) for the evaluation of multifunctional landscape according to a human smart perspective [57]. In the C-MC SDSS, awareness and multidimensional reading of the landscape are considered the two important focuses for a smart local development. In the East Mediterranean, there is no evidence of effective public participation in the decision-making process. In Lebanon, for example, top-down "modernist" urban planning approaches-which continuously favor local elites such as politicians and landowners and pay little attention to social and community interests-are still commonly observed [61]. Citizens' involvement in the planning process is implemented in only a few scattered situations. Furthermore, stakeholder involvement in the LCA process during the MEDSCAPES project was not very successful due to the low rate of responses we were able to collect through the interviews we conducted during the first phase of the project. Thus, we were not able to incorporate the insufficient data gathered in the LDSS database, but we aimed at spreading awareness on landscape related topics by visualizing through our user's interface the effects that today's actions could produce in our territories in the East Mediterranean. Through workshop and seminars training we were able to introduce the audience to the interface and to let them visualize, for example, the consequences that the spread of urbanization could have on future development and, in particular, on the landscape seen as a human-ecologic system, which can offer a wide range of benefits with positive effects on the quality of life of the local community. On the other hand, our tool foresees the user's interaction as manipulation of rank and weight of indicators with particular emphasis on intensification of urban sprawl and ecological integrity. The user-friendly interface allows multiple users to provide input and generate real-time output to support negotiated spatial decisions [62]. The LDSS framework, through weighing and evaluating alternatives, will help decision makers in conceptualizing alternatives and thus in considering the related decisions for future planning. Once an alternative is selected and implemented the results could be compared with the produced scenarios and then a revaluation of the criteria could be done. The scenarios act as crucial bridges between environmental/landscape science and policy. They influence policymaking by summarizing and synthesizing scientific knowledge in a form that can be used by policymakers to develop policies [63]. Our method, which did not incorporate quantitative information on the public preferences and values attributed to the landscape, has the advantage of being easy to perform and it has the capacity to easily communicate the outcomes of the LCA and LRA to a large and diverse audience through the scenarios' maps; it also has the benefit of being interactive, thus giving to the users the possibility to manipulate the data and spatially visualize the related scenarios.

We believe it is necessary to underline that the LDSS is a first-level tool and a result of the research conducted during the length of the MEDSCAPES project. It was conceived in a way to be further upgraded by integrating up-to-date info in order to produce more credible scenarios and in order 
for the involved parties to be able to use it and to further adapt it to their need and regulations. The workshops and the training session between the MEDSCAPES developers and the interested end-users (regional and planning department, ministries, etc.) allowed us to test the tool and to identify problems and options in order to ameliorate and calibrate the system to a more context-based situation. In Lebanon, for instance, the LDSS is in the process of revision and development under the Food and Agriculture Organization of the United Nations (FAO) grant 'Forest and Landscape Restoration Mechanism'. Thus, it has been further adjusted in order to better fit the research objective and to assess, and map the loss of landscape character in relation to the forested LDUs, and to develop scenarios of the different probabilities of landscape character loss/change under the threats of different hazards. Like other methods, such as DESYCO [6], our tool could be applied in different geographical contexts, and spatial scales, however, it does not overcome the issue of uncertainty assessment toward some of the indicators and it does not allow an evaluation of social risk perception.

\section{Conclusions}

This study, conducted at the regional scale of the Eastern Mediterranean basin, is an important attempt to assess and collate the landscape character of the region by individuating and using comparable indicators to evaluate the risk of loss of the landscape value of the East Mediterranean region. Furthermore, the LDSS enables users and stakeholders to build helpful scenarios in the planning process of the selected areas. The generation and selection of scenarios advocate for a bottom-down approach to landscape planning that could complement the conventional practice, and it constitutes a step forward into sustainable land use protection and management. Many authors have supported the use of risk assessment and decision analysis in the selection of implementable solutions to environmental problems [64], however, only a small number of studies integrate different landscape features, such as land-use, vegetation, geology, hydrography, cultural and archaeological elements into the assessment methods [24]. Our model was successful in incorporating and working ecological and cultural features of the East Mediterranean landscape but did not take into consideration the socio-economical and human health components. The reason lays in the objectives of the research and in the typology of landscape assessment the partners of the project agreed on using to conduct our study. Results show the importance of landscape protection policies in addressing the main threats to landscape values with particular regards towards the urban sprawl processes whose consequences on the landscape as a whole are of great magnitude.

The methodology was designed using previously tested research studies that, following a comparison to our objectives, were reworked and adapted to better suit the aim of our study. It focuses mainly on the physical components of the landscape that were evaluated under the landscape ecology lens with the incorporation of few cultural assets. Though limited, these assets were important in portraying a more thorough picture of the Mediterranean landscape character and of the threats to which it is subjected.

The opportunities presented by a landscape-based approach for the European continent mark out the landscape as a possible new paradigm for a local development model, with the aim of harmonious integration of social, economic, and environmental factors in space and time [65]. It represented an important step in the individuation of a method and related tool that is able to assess and compare the Landscape Risk at the scale of the Eastern Mediterranean basin. Furthermore, the methodology and framework developed within the MedScapes project are playing an important and strategic role in advocating the importance of the landscape in the planning process, and in spreading awareness on the protection and management of natural and cultural heritage in the Eastern Mediterranean region.

The designed LRA and LDSS tools require further development that could allow the system to incorporate the assessment of socio and economic factors related to the landscape character of the East Mediterranean Region in general and to the selected countries in particular. This inclusion will portray more holistic and inclusive scenarios, thus allowing the possibility for the monetary consequence of the assessed landscape loss and its repercussions on social wellbeing to be estimated and quantified. 
Acknowledgments: The research was conducted with the financial support of the cross-border cooperation 'Mediterranean Sea Basin Programme-ENPI' of the European Union. The grant is not supporting the costs to publish in open access. Maria Gabriella Trovato wants to express her gratitude to her University, AUB, and her department in particular, LDEM, for the support and help throughout the duration of the project. A special thanks to all the governmental institutions that directly and indirectly contributed to the smooth development of the research by giving access to resources and data necessary to run our project.

Author Contributions: Maria Gabriella Trovato and Dana Ali conceived and designed the experiments; Jessica Nicolas and Ammar El Halabi performed the experiments; Jessica Nicolas, Dana Ali, and Ammar El Halabi analyzed the data; Maria Gabriella Trovato, Dana Ali, and Sarah Meouche wrote the paper.

Conflicts of Interest: The authors declare no conflict of interest. The founding sponsors had no role in the design of the study; in the collection, analyses, or interpretation of data; in the writing of the manuscript, and in the decision to publish the results.

\section{References}

1. Nogué, J.; Wilbrand, S.M. Landscape identities in Catalonia. Landsc. Res. 2017, 1-12. [CrossRef]

2. Secretary of State for Foreign and Commonwealth Affairs. European Landscape Convention, Florence; Treaty Section, Foreign and Commonwealth Office: London, UK, 2000.

3. Kapustka, L.; Galbraith, H.; Luxon, M.; Yocum, J. Using landscape ecology to focus ecological risk assessment and guide risk management decision-making. Toxicol. Ind. Health 2001, 17, 236-246. [CrossRef] [PubMed]

4. Kochanek, K.; Tynan, S. The environmental risk assessment for decision support system for water management in the vicinity of open cast mines (ds wmvoc). Ukio Technol. Ekon. Vystym. 2010, 16, 414-431. [CrossRef]

5. ARMONIA Project. Report on the European scenario of technological and scientific standards reached in spatial planning versus natural risk management. In The Adaptiveness of IWRM: Analysing European IWRM Research; Timmerman, J., Pahl-Wostl, C., Moltgen, J., Eds.; IWA: London, UK, 2008.

6. Torresan, S.; Critto, A.; Rizzi, J.; Zabeo, A.; Furlan, E.; Marcomini, A. DESYCO: A decision support system for the regional risk assessment of climate change impacts in coastal zones. Ocean Coast. Manag. 2016, 120, 49-63. [CrossRef]

7. Agostini, P.; Pizzol, L.; Critto, A.; D'Alessandro, M.; Zabeo, A.; Marcomini, A. Regional risk assessment for contaminated sites Part 3: Spatial decision support system. Environ. Int. 2012, 48, 121-132. [CrossRef] [PubMed]

8. Brown, G.; Braby, L. An analysis of the relationships between multiple values and physical landscapes at a regional scale using public participation GIS and landscape character classification. Landsc. Urban Plan. 2012, 107, 317-331. [CrossRef]

9. Beverly, J.; Uto, K.; Wilkes, J.; Bothwell, P. Assessing spatial attributes of forest landscape values: An internet-based participatory mapping approach. Can. J. For. Resour. 2008, 38, 289-303. [CrossRef]

10. Brown, G.; Reed, P. Validation of a forest values typology for use in national forest planning. For. Sci. 2000, 46, 240-247.

11. Clement, J.M.; Cheng, A.S. Using analyses of public value orientations, attitudes and preferences to inform national forest planning in Colorado and Wyoming. Appl. Geogr. 2010, 31, 393-400. [CrossRef]

12. Brown, G.; Weber, D. Measuring change in place values using public participation GIS (PPGIS). Appl. Geogr. 2012, 34, 316-324. [CrossRef]

13. Tyrväinnen, L.; Mäkinen, K.; Schipperijn, J. Tools for mapping social values of urban woodlands and other green areas. Landsc. Urban Plan. 2007, 79, 5-19. [CrossRef]

14. Brown, G. Mapping landscape values and development preferences: A method for tourism and residential development planning. Int. J. Tour. Res. 2006, 8, 101-113. [CrossRef]

15. Raymond, C.; Brown, G. A spatial method for assessing resident and visitor attitudes toward tourism growth and development. J. Sustain. Tour. 2007, 15, 520-540. [CrossRef]

16. Alessa, N.; Kliskey, A.; Brown, G. Social-ecological hotspots mapping: A spatial approach for identifying coupled social-ecological space. Landsc. Urban Plan. 2008, 85, 27-39. [CrossRef]

17. Nielsen-Pincus, M. Land Use, Resource Management, and Place: A Case Study in Three Counties of Northern Idaho and Northeastern Oregon. Ph.D. Thesis, University of Idaho, Moscow, ID, USA, 2007.

18. Pocewicz, A.; Schnitzer, R.; Nielsen-Pincus, M. The Social Geography of Southern Wyoming: Important Places, Development, and Natural Resource Management; The Nature Conservancy: Lander, WY, USA, 2010; 16p. 
19. Raymond, C.; Brown, G. Assessing spatial associations between perceptions of landscape value and climate change risk for use in climate change planning. Clim. Chang. 2011, 104, 653-678. [CrossRef]

20. La Rosa, D. The observed landscape: Map of visible landscape values in the province of Enna (Italy). J. Maps 2011, 7, 291-303. [CrossRef]

21. Meyer, B.C.; Grabaum, R. MULBO: Model framework for multicriteria landscape assessment and optimization. A support system for spatial land use decision. Landsc. Res. 2008, 33, 155-179. [CrossRef]

22. Clay, G.R.; Daniel, T.C. Scenic landscape assessment: The effects of land management jurisdiction on public perception of scenic beauty. Landsc. Urban Plan. 2000, 49, 1-13. [CrossRef]

23. Meyer, B.C. Landscape assessment. In Landscape Balance and Landscape Assessment; Krönert, R., Steinhardt, U., Volk, M., Eds.; Springer: Berlin/Heidelberg, Germany, 2001; pp. 203-250.

24. La Rosa, D.; Martinico, F. Assessment of hazards and risks for landscape protection planning in Sicily. J. Environ. Manag. 2013, 127, S155-S167. [CrossRef] [PubMed]

25. Antrop, M. Sustainable landscapes: Contraction, fiction or utopia. Landsc. Urban Plan. 2006, 75, $187-197$. [CrossRef]

26. Bacon, C.M. Disaster Risk and Sustainable Development. In The Routledge Handbook of Hazards and Disaster Risk Reduction; Wisner, B., Gaillard, J.C., Kelman, I., Eds.; Routledge: London, UK, 2011; pp. 156-167.

27. Dransch, D.; Etter, J.; Walz, U. Maps for natural risk management. In Proceedings of the 22nd International Cartographic Conference, La Coruna, Spain, 9-16 July 2005.

28. Menoni, S.; Margottini, C. Inside Risk: A Strategy for Sustainable Risk Mitigation; Foreword; Springer: Milan, Italy, 2011.

29. Walker, G.; Deeming, H.; Margottini, C.; Menoni, S. Introduction to Sustainable Risk Mitigation for a more resilient Europe. In Inside Risk: A Strategy for Sustainable Risk Mitigation; Foreword; Menoni, S., Margottini, C., Eds.; Springer: Milan, Italy, 2011.

30. Martinico, F.; La Rosa, S.D. The Use of GIS in Landscape Protection Plan in Sicily. In Urban and Regional Data Management (UDMS) Annual 2009; Krek, A., Rumor, M., Zlatanova, S., Fendel, E., Eds.; Taylor \& Francis: London, UK, 2009; pp. 315-325.

31. De Ayala, A.; Hoyos, D.; Mariel, P. Suitability of discrete choice experiments for landscape management under the European Landscape Convention. J. For. Econ. 2015, 21, 79-96. [CrossRef]

32. Johnston, R.J.; Duke, J.M. Willingness to pay for agricultural land preservation and policy process attributes: Does the method matter? Am. J. Agric. Econ. 2007, 89, 1098-1115. [CrossRef]

33. Burley, J.B.; Burley, C.J. A risk assessment of landscape hazards for building sites in the Front Range Mountains of Colorado. Landsc. Res. 1996, 21, 137-158. [CrossRef]

34. Fernandes, J.P. Landscape ecology and conservation management e evaluation of alternatives in a highway EIA process. Environ. Impact Assess. Rev. 2000, 20, 665-680. [CrossRef]

35. Antrop, M. Background concepts for integrated landscape analysis. Agric. Ecosyst. Environ. 2000, 77, 17-28. [CrossRef]

36. Williamson, D. Scenic perceptions of Australian landscapes. Landsc. Aust. 1979, 2, 94-101.

37. Leonard, M.; Hammond, R. Landscape Character Types of Victoria-With Frames of Reference for Scenic Quality Assessment; Forest Commission of Victoria: Melbourne, Australia, 1984.

38. Daniel, T.C.; Vining, J. Methodological Issues in the assessment of landscape quality. In Behaviour and the Natural Environment; Altman, I., Wohwill, J.F., Eds.; Plenum Press: New York, NY, USA, 1983; pp. $39-83$.

39. Regional Forest Agreements Act 2002. Australia.

40. Butler, A. Dynamics of integrating landscape values in landscape character assessment: The hidden dominance of the objective outsider. Landsc. Res. 2016, 41, 239-252. [CrossRef]

41. Brown, G. Mapping spatial attributes in survey research for natural resource management: Methods and applications. Soc. Nat. Resour. 2004, 18, 17-39. [CrossRef]

42. Brown, G.; Raymond, C. The relationship between place attachment and landscape values: Toward mapping place attachment. Appl. Geogr. 2007, 27, 89-111. [CrossRef]

43. Brown, G.; Raymond, C.M. Methods for identifying land use conflict potential using participatory mapping. Landsc. Urban Plan. 2014, 122, 196-208. [CrossRef]

44. Jones, M. Analysing landscape values expressed in planning conflicts over change in the landscape. In Re-Marc-able Landscapes: Marc-ante Landschappen; Eetvelde, V., Van Sevenant, M., Van De Velde, L., Eds.; Academia Press: Gent, Belgium, 2009; pp. 193-205. 
45. Stephenson, J. The cultural values model: An integrated approach to values in landscapes. Landsc. Urban Plan. 2008, 84, 127-139. [CrossRef]

46. Henningsson, M.; Blicharska, M.; Antonson, H.; Mikusiński, G.; Göransson, G.; Angelstam, P.; Jönsson, S. Perceived landscape values and public participation in a road-planning process-A case study in Sweden. J. Environ. Plan. Manag. 2014, 58, 631-653. [CrossRef]

47. Hay, R. A rooted sense of place in cross-cultural perspective. Can. Geogr. 1998, 42, 245-266. [CrossRef]

48. Gray, J. A rural sense of place: Intimate experience in planning a countryside for life. Plan. Theory Pract. 2013, 4, 93-96. [CrossRef]

49. De Angelis, D.L.; Pearlstine, L.; Mazzotti, F.J.; Barnes, T.; Duever, M.; Starners, J. Spatial Decision Support Systems for Landscape Ecological Evaluations in the Southwest Florida Feasibility Study; US Geological Survey Report; U.S. Department of the Interior: Washington, DC, USA, 2004.

50. Greiving, S.; Fleischhauer, M.; Lückenkötter, J. A methodology for an integrated risk assessment of spatially relevant hazards. J. Environ. Plan. Manag. 2006, 49, 1-19. [CrossRef]

51. Rauscher, H.M. Ecosystem management decision support for Federal forests in the United States: A review. For. Ecol. 1999, 114, 173-197. [CrossRef]

52. He, J.; Sun, Y. Applying a spatial decision support system to the integrated regional planning of China. Environ. Plan. B Urban Anal. City Sci. 2015, 42, 1161-1176. [CrossRef]

53. Fedra, K.; Feoli, E. GIS technology and spatial analysis in coastal zone management. EEZ Technol. 1998, 3, 171-179.

54. Wilkerson, G.W.; McAnally, W.H.; Martin, J.L.; Ballweber, J.A.; Pevey, K.C.; Diaz-Ramirez, J.; Moore, A. Latis: A spatial decision support system to assess low-impact site development strategies. Adv. Civ. Eng. 2010. [CrossRef]

55. Simoes, M. GIS and spatial decision support system for environmental degradation monitoring. In Proceedings of the 7th International Seminar on GIS in Developing Countries, Johor, Malaysia, 10-12 May 2004.

56. Nakicenovic, N.; Alcamo, J.; Davis, G.; de Vries, H.J.M.; Gaffin, S.; Gregory, K.; Grubler, A.; Jung, T.Y.; Kram, T.; Lebre La Rovere, E.; et al. Intergovernmental Panel on Climate Change (IPCG) Special Report on Emission Scenarios (SRES); Intergovernmental Panel on Climate Change (IPCC): Geneva, Switzerland, 2000.

57. Attardi, R.; Cerreta, M.; Poli, G. A Collaborative Multi-Criteria Spatial Decision Support System for Multifunctional Landscape Evaluation. In Computational Science and Its Applications-ICCSA 2015; Lecture Notes in Computer Science; Gervasi, O., Murgante, B., Misra, S., Gavrilova, M.L., Rocha, A.M.A.C., Torre, C.M., Taniar, D., Apduhan, B.O., Eds.; Springer: Cham, Switzerland, 2015.

58. Alcamo, J. Scenarios as Tools for International Environmental Assessments; Environmental Issue Report; European Environment Agency (EEA): Copenhagen, Denmark, 2001.

59. Frede, H.-G.; Bach, M.; Fohrer, N.; Möller, D.; Steiner, N. Multifunktionalitat der Landschaft-Methoden und Modelle. Petermanns Geogr. Mitt. 2002, 146, 58-63.

60. Ryan, R.L.; Fábos, J.G.; Allan, J.J. Understanding opportunities and challenges for collaborative greenway planning in New England. Landsc. Urban Plan. 2006, 76, 172-191. [CrossRef]

61. El Asmar, E.A.; Ebohonb, J.O.; Taki, A. Bottom-up approach to sustainable urban development in Lebanon: The case of Zouk Mosbeh. Sustain. Cities Soc. 2012, 2, 37-44. [CrossRef]

62. Arciniegas, G.; Janssen, R. Spatial decision support for collaborative land use planning workshops. Landsc. Urban Plan. 2012, 107, 332-342. [CrossRef]

63. Urban and Regional Data Management. UDMS Annual 2009; Krek, A., Rumor, M., Zlatanova, S., Fendel, E.M., Eds.; Taylor \& Francis: London, UK, 2009.

64. Bonanno, E.J.; Apostolakis, G.E.; Salter, P.F.; Ghassemi, A.; Jennings, S. Application of risk assessment and decision analysis to the evaluation, ranking and selection of environmental remediation alternatives. J. Hazard. Mater. 2000, 71, 35-57. [CrossRef]

65. Agnoletti, M. Rural landscape, nature conservation and culture: Some notes on research trends and management approaches from a (southern) European perspective. Landsc. Urban Plan. 2004, 126, 66-73. [CrossRef]

(C) 2017 by the authors. Licensee MDPI, Basel, Switzerland. This article is an open access article distributed under the terms and conditions of the Creative Commons Attribution (CC BY) license (http:/ / creativecommons.org/licenses/by/4.0/). 